\title{
Estudio histórico-arqueológico de la muralla sureste de Arcos de la Frontera (Cádiz)
}

\section{Historical and archaeological study of the south-eastern city wall of Arcos de la Frontera (Cadiz)}

\author{
Manuel María Alonso-Ruiz \\ Centro de Estudios de Arqueología Bastetana, Baza, Granada \\ e-mail: manuelmariaalonso@hotmail.com \\ Luis J osé García-Pulido \\ LAAC, Escuela de Estudios Árabes de Granada, CSIC \\ e-mail: luis.garcia@eea.csic.es
}

\section{RESUMEN}

Con motivo del proyecto elaborado por los técnicos del Ayuntamiento de Arcos de la Frontera para la restauración del tramo de muralla medieval conservada en el sureste de esta localidad, los autores de este artículo realizaron la intervención arqueológica, documentación planimétrica y estudio de dicha cerca. Como resultado de estas actuaciones se han identificado ocho períodos edificatorios, agrupados en tres grandes ciclos. De cara a obtener una mayor comprensión del objeto de estudio, estas actuaciones se han completado con el recurso a las fuentes escritas, la prospección urbana, el estudio de la microtoponimia, la analogía con otros elementos arquitectónicos y, en menor medida, con la información aportada por los materiales arqueológicos. Los resultados de estos análisis permiten el planteamiento de una hipótesis razonable para la fundación de la muralla y la relación entre las tres puertas históricas del frente suroriental de la localidad. Las conclusiones obtenidas suponen un acercamiento a la evolución urbana de esta zona de Arcos de la Frontera desde época andalusí hasta las postrimerías de la Edad Moderna.

Palabras clave: Poliorcética medieval; Arqueología de la Arquitectura; materiales y técnicas constructivas históricas; muralla andalusí; levantamiento fotogramétrico.

\begin{abstract}
Due to the project developed by the technicians of the Municipality of Arcos de la Frontera in order to restore the visible remains of the Medieval wall preserved in the southeastern area of this town, the authors of this paper conducted the archaeological excavation, drawing survey and study of this enclosure. As a result of these analysis have been identified eight constructive periods, grouped into three cycles. With the aim of obtaining a better understanding of this monument, these activities have been completed with the use of written sources, the urban fieldwork, the study of micro-toponymy, the analogy with other architectural elements and, to a lesser extent, with the information provided by the archaeological materials. The results of these analyses make possible to propose a reasonable hypothesis regarding the foundation of the wall and the relationship between its three southeastern gates. The conclusions mean an approach to the urban development of this area of Arcos de la Frontera from al-Andalus times until the late Modern Age.
\end{abstract}

Keywords: Medieval poliorcetic; Archaeology of Architecture; materials and historical building techniques; alAndalus city walls; photogrammetric survey.

Recibido: 19/10/2012. Aceptado: 24/6/2013.

Cómo citar este artículo / Citation

Alonso-Ruiz, M. M. a y García-Pulido, L. J. 2013: "Estudio histórico-arqueológico de la muralla sureste de Arcos de la Frontera (Cádiz)",

Arqueología de la Arquitectura, 10: e004. doi: http://dx.doi.org/10.3989/arq.arqt.2013.005

\section{Copyright}

(c) 2013 CSIC. Este es un artículo de acceso abierto distribuido bajo los términos de la licencia Creative Commons Attribution-Non Commercial (by-nc) Spain 3.0. 
Fig. 1. Ubicación del tramo conservado de la muralla sureste de Arcos de la Frontera. Emplazamiento de los sondeos arqueológicos en el subsuelo y en los paramentos de las edificaciones adosadas a la muralla en el entorno de la Puerta del Cómpeta (zona 1) y del Arco de Matrera (zona 2)
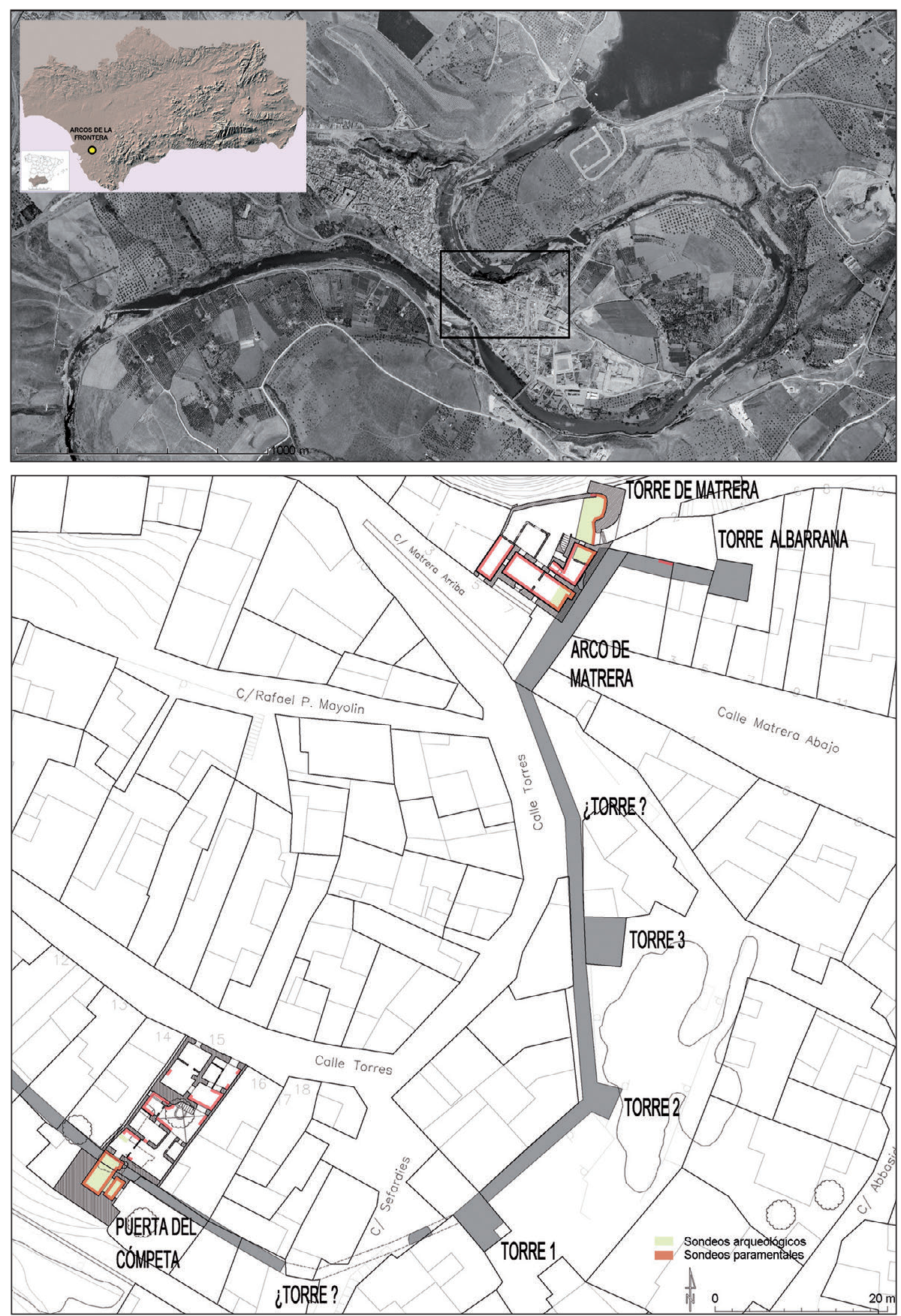

\section{I NTRODUCCI ÓN}

La intervención patrimonial realizada sobre la muralla sureste de Arcos de la Frontera ha sido la primera de esta naturaleza que se ha efectuado sobre este Bien de Interés Cultural ${ }^{1}$. Nuestro estudio se ha desarrollado sobre un frente de muralla y dos inmuebles asociados al mismo (Fig. 1). El objetivo fundamental ha consistido

1 Según la descripción adicional segunda de la ley 16/85 de Patrimonio Histórico, Grado 1. en la comprensión diacrónica de la muralla y de ambas viviendas, lo que traducido a una escala aún mayor supone una aproximación a la propia historia del municipio, prestando especial atención a momentos de relevancia social, económica y cultural que han dejado huella en el patrimonio edificado de Arcos de la Frontera.

El análisis también pretendía esclarecer el origen del único paso a través de la muralla arcense que sigue estando en uso, conocido localmente como Arco de Matrera (Fig. 2), así como obtener unas conclusiones técnicas — relativas 


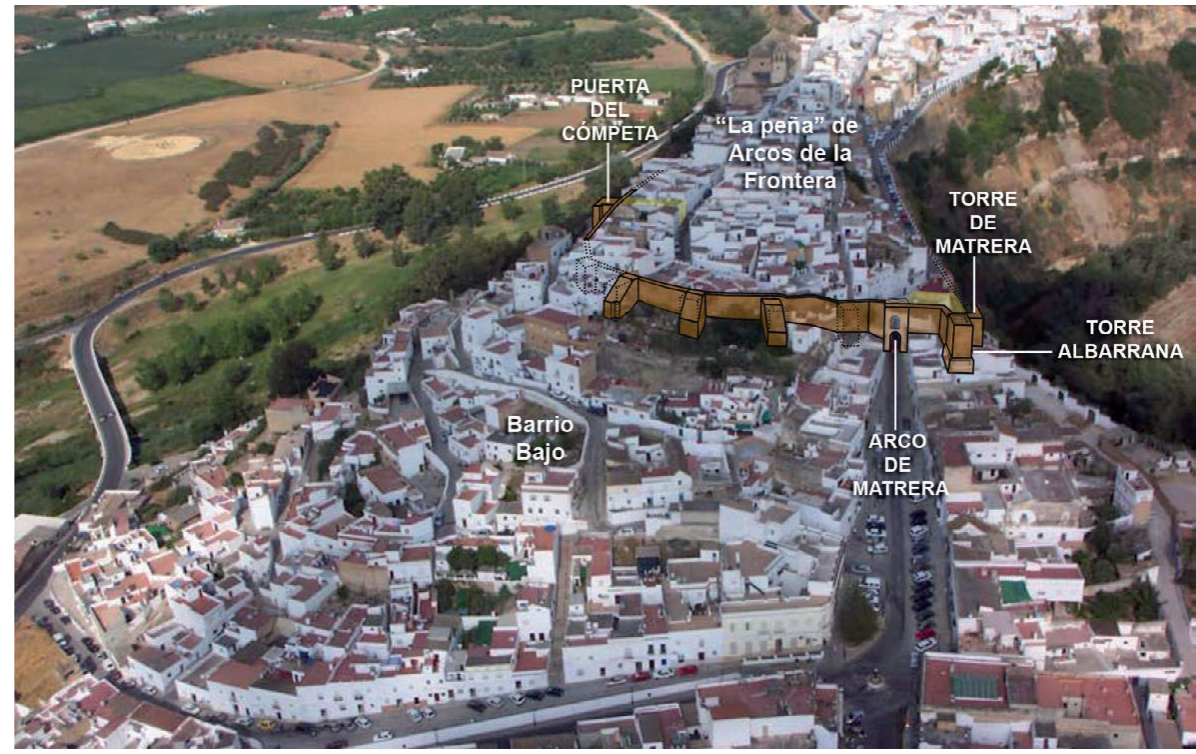

Fig. 2. Vista aérea oblicua de la zona sureste del Arcos de la Frontera, en la que se ha resaltado el tramo de muralla conservado en el caserío actual sobre todo a la materialidad de las estructuras y patologías de las mismas - que se tradujesen en pautas para una posterior restauración. Desafortunadamente la descontextualización de gran parte de los materiales arqueológicos, así como los desmontes efectuados en distintos momentos históricos sobre la roca natural, nos han impedido alcanzar otro de los objetivos prioritarios del estudio como era establecer la fecha fundacional de la muralla, pese a lo cual trataremos de establecer una hipótesis razonable.

El desarrollo de nuestra investigación se puede dividir en dos etapas bien definidas:

- Una primera en la que, junto al análisis estratigráfico y tipológico de los restos emergentes, hemos practicado algunos sondeos puntuales en el subsuelo. Esta fase se ha completado con un muestreo de medidas de ladrillos que no ha constituido un estudio mensiocronológico en sí, debido a la carencia de un patrón inicial bien datado.

- Una segunda fase, desarrollada en campo y laboratorio, donde se ha prospectado el casco histórico y el territorio aledaño en torno al río Guadalete y se han analizado las fuentes escritas sobre la muralla y la propia villa, la microtoponimia, la cartografía y el estudio analógico con otras estructuras arquitectónicas.

El trabajo que aquí presentamos ha sido estructurado en cinco apartados:

- Introducción: supone unas breves pinceladas donde presentamos el estudio desarrollado, la estrategia de intervención y los objetivos de la actuación.
- Evolución histórica de Arcos de la Frontera y sus murallas: a partir de la historiografía y las fuentes escritas se recogen algunos apuntes sobre la historia arcense desde el siglo VIII, prestando una mayor atención a los datos referidos a la cerca.

- Descripción de las dos zonas de intervención y del proceso de trabajo: presentación de los dos inmuebles adosados a la muralla en los que se ha actuado, más un tercer subapartado donde explicamos el proceso de trabajo seguido, algunas notas sobre la metodología y nomenclatura empleada, así como la sectorización de las zonas de actuación.

- Análisis estratigráfico: se han identificado ocho procesos edificatorios (subfases) agrupados en tres grandes fases cronoculturales (andalusí, bajomedieval y moderna). A su vez el último punto de la fase andalusí lo dedicamos a exponer algunos argumentos que nos permitan adscribir la muralla cronológicamente.

- Conclusiones: reseñamos algunos aspectos que nos han parecido importantes a la hora de interpretar la evolución de las estructuras. Por último, concluimos dedicando unas líneas a las tres puertas históricas que se han localizado en el frente sureste de la muralla arcense $^{2}$ (Fig. 3), planteando una hipótesis global acerca de su origen, uso y amortización.

\footnotetext{
2 La que hemos denominado como Puerta del Cómpeta (por encontrarse situada en el barrio del mismo nombre), el Arco de Matrera y el paso de la calle Cardenal Espínola. Solo la primera ha llegado a nuestros días con una planta en recodo.
} 

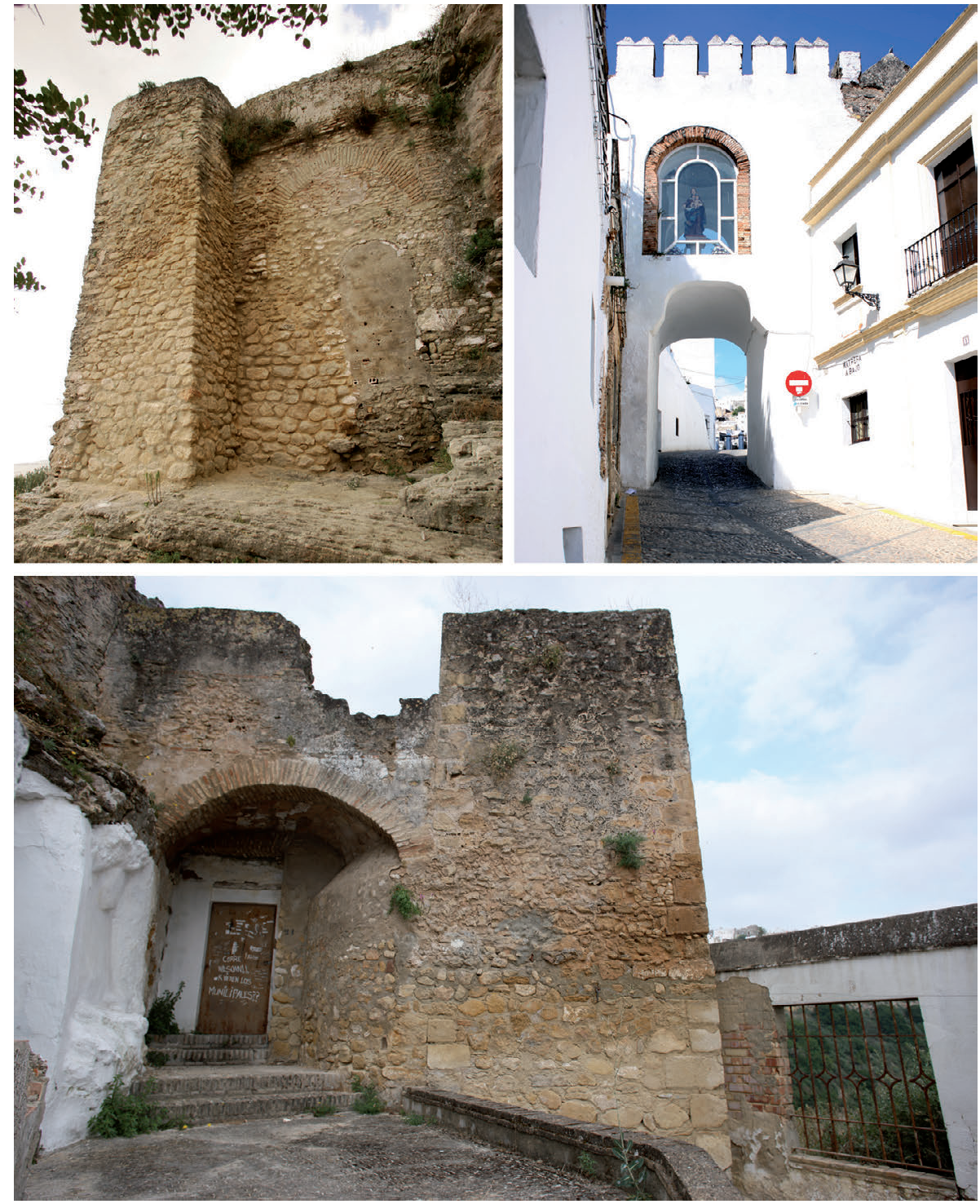

Fig. 3. Puerta del Cómpeta (arriba izquierda), Arco de Matrera visto desde la calle Matrera Abajo (arriba derecha) y paso sobre la muralla existente en la calle Cardenal Espínola, flanqueado por la Torre de Matrera (abajo)

\section{EVOLUCIÓN HISTÓRICA DE ARCOS DE LA FRONTERA Y SUS MURALLAS: HI STORI OGRAFÍ A Y FUENTES ESCRITAS}

Sobre el promontorio rocoso en el cual se asienta esta población (en adelante utilizaremos el término coloquial, "la peña”), existió una fortaleza al menos desde época andalusí temprana, tal como se deduce a partir de Una descripción anónima de al-Andalus, fuente cronística y geográfica bajomedieval. En la misma, Arkus (Arcos de la Frontera) es definido como un castillo cuya fundación “... se remonta a tiempos muy lejanos, pues fue construida por los antiguos, que la llamaron Qal at al-Nusur (Fortaleza de las Águilas)”’3. La mención más antigua

\footnotetext{
Molina 1983: pp. 70-71.
}

de Arkus para época andalusí nos remite a mediados del siglo VIII y los textos medievales islámicos indican que durante la etapa emiral fue destruida dos veces ${ }^{4}$.

Ya en el siglo $\mathrm{X}$, las fuentes escritas mencionan la fortaleza arcense en un par de ocasiones. La primera, como residencia de un alto ex-funcionario de la corte omeya $^{5}$, y la segunda con motivo de la aceifa de 914, segunda campaña de 'Abd al-Rahman III al-Nasir por la Baja Andalucía 6 .

\footnotetext{
4 Viguera 2003: p. 43.

5 "En aquel año fue depuesto Yahwar b. `Abdalmalik al-Bujti del visirato en rabi I (5 octubre-3 noviembre 913), cargo al que ya no volvió, pues permaneció depuesto hasta fallecer en la fortaleza de Arcos, de la cora de Sidonia, a comienzos del muharram del 312 (9 de abril 924)"; Ibn Hayyan 1981: p. 84.

6 "De Calcena, el ejército partió y fue a acampar frente a la fortaleza de Arcos, donde estaba Numara b. Sulayman, hermano de ar-Ruhayni, el huido del ejército, a quien sitió an-Nasir..."; Ibn Hayyan 1981: p. 77.
} 
Debemos señalar que durante estos siglos Arcos de la Frontera quedó inscrita en la kura de Sidonia ${ }^{7}$ como una de sus principales ciudades, llegando en ocasiones a ejercer de capital de la misma además de Medina Sidonia, tal como sucedió también con Calsena ${ }^{8}$ o Jerez de la Frontera $^{9}$. En opinión de Viguera Molins ${ }^{10}$, el fenómeno del traslado de la capital de la kura, así como el cambio de topónimo — de Qal at al-Nusur a Arkus - podría estar relacionado con la siguiente cita que nos transmite al-Himyari en época bajomedieval, basándose a su vez en testimonios previos: “... es una fortaleza (hisn) sobre el Guadalete. Es una ciudad que data de la antigüedad; ha sido destruida varias veces, después repoblada. Su territorio encierra numerosos olivos..."11.

En el siglo XI Arkus contó con taifa propia regida por una dinastía beréber hasta el año $1066^{12}$. Precisamente en este contexto contamos con una primera referencia para las defensas de la localidad, ya que en el año 1011 el primero de los régulos, Muhammad: “... se apoderó de Arcos (Arkus) que es una de las más importantes fortalezas de al-Andalus, y la dominó. Estableció en ella su soberanía, consolidando sus defensas e incrementándola en riquezas..." ${ }^{13}$.

Algo más prolijas son las fuentes árabes para los dos siglos siguientes, cuando la población experimentó un notable crecimiento al amparo de su condición de escala para los ejércitos de los imperios norteafricanos durante sus campañas en al-Andalus, tal como sucedió por ejemplo en 1190 con las huestes almohades ${ }^{14}$. Unas pocas décadas antes, durante las segundas taifas, Arkus había sido la primera en someterse a los Unitarios ${ }^{15}$ en $1148^{16}$, mientras que por esas mismas fechas el sufí Ibn Qasi también les prestaba juramento en el hisn Arkus ${ }^{17}$. Durante esta centuria, al-Idrisi incluyó este asentamiento

\footnotetext{
Mazzoli-Guintard 1996: p. 237.

8 El yacimiento de origen romano de Calsena o Qalsana se encuentra en Junta de los Ríos, pedanía situada a $7 \mathrm{~km}$ de Arcos de la Frontera. De su importancia en época andalusí, tenemos constancia a través de las fuentes escritas y de algunas intervenciones arqueológicas efectuadas en su antiguo solar desde 1988, las cuales han identificado una trama urbana asociada, al menos, a una alcazaba y a un cementerio; Richarte y Aguilera 2003: pp. 87-102.

9 El traslado de la capitalidad de una kura no fue un fenómeno exclusivo de Sidonia, ya que ocurrió entre otras, con Yayyan y Rayya; Vallvé 1986: pp. 325-326.

10 Viguera, 2003: p. 39, n. 5. Sobre la kura de Sidonia puede consultarse:

Toledo 1985-1986.

11 al-Himyari 1963: p. 40.

12 B. Buluqqin al-Ziri 1980: p. 31

13 Maíllo 1991: p. 27.

14 Triki 1999: p. 197.

15 al-Muwahhidun, como se denominaban a sí mismos los Almohades.

${ }_{16}$ Ibn Abi Zar` 1964: pp. 375-376.

17 Ibn Jaldun 2008: p. 272.
}

en el distrito (iqlim) de Lac, junto a Tarifa, Algeciras, Cádiz, Beca y Jerez de la Frontera ${ }^{18}$, mientras que Ibn Sa'id lo define como kura y máquil perteneciente al reino —mamlaka- de Sevilla ${ }^{19}$.

Al amparo de las grandes conquistas de la Bética iniciadas por Fernando III, será su hijo el infante D. Enrique quién en 1253 conquiste Arkus a los musulmanes $^{20}$, los cuales la volverían a ocupar momentáneamente entre 1261 y 1264 , momento en el cual Alfonso $\mathrm{X}$ la integró definitivamente en la Corona de Castilla ${ }^{21}$. A partir de este momento asistimos a la configuración de la nueva realidad geopolítica y socioeconómica que será la frontera ${ }^{22}$. Desde entonces Arcos de la Frontera ${ }^{23}$ tendrá carácter de colonia o presidio militar, situación que perdurará durante toda la Baja Edad Media.

Encontramos en las fuentes escritas de aquellos siglos algunas alusiones donde se nos da cuenta del estado de las murallas y del castillo, así como del acusado vacío demográfico que padeció la villa. Contamos con dos interesantes testimonios para finales del siglo XIII, en el primero de los cuales Arcos de la Frontera aparece como residencia de tan solo ocho caballeros ${ }^{24}$. El otro documento es una relación de gastos de las plazas fronterizas más expuestas de la comarca del Guadalete, emitido en 1294 con motivo de la campaña granadino-meriní. Según cálculos hipotéticos realizados por García Fitz ${ }^{25}$, los peones disponibles para la defensa de dicha población durante esta época oscilarían entre sesenta y ciento veinte.

El problema de la despoblación debió ser tan acuciante por estas fechas, que Arcos de la Frontera ni siquiera aparece presente en las asambleas de Hermandades de la Baja Andalucía desarrolladas entre 1295 y $1320^{26}$. Para paliar esta situación y salvaguardar la defensa del enclave, Alfonso XI pone la villa con todo

\footnotetext{
${ }_{18}$ Mazzoli-Guintard 1996: p. 239, n. 8.

19 Mazzoli-Guintard 1996: p. 241.

20 A pesar de que la Crónica de Alfonso X proporciona la errónea fecha de 1255; Vid. González Jiménez 2003: p. 12.

${ }^{21}$ Mancheño 2002: vol. I, pp. 32-33.

22 Ingente es la producción historiográfica sobre la frontera bajomedieval hispana en sus diversas zonas y períodos. Por ser de nuestro mayor interés, remitimos a las Actas del I Congreso de Historia de Arcos de la Frontera.

${ }^{23}$ Este apelativo -de la Frontera- aparece por vez primera en un Privilegio Real de Fernando IV datado en 1300; Mancheño 2002: vol. I, p. 49.

${ }^{24}$ El mismo número de caballeros con que contaba Baeza y uno más que Carmona. A gran distancia se encontraba Jerez de la Frontera con cincuenta y Sevilla con ochenta y cinco. Por otra parte este exiguo número de ocho caballeros se asocia a los nueve que, según la tradición, repoblaron Arcos desde Sevilla por orden de Alfonso X; Vid. Hernández 1993: pp. 391-405.

${ }_{25}$ García 1988: pp. 31-32.

26 Estas asambleas reunieron a casi todos los concejos andaluces para unificar posturas ante asuntos de común interés; Sánchez 2003: pp. 201-202.
} 


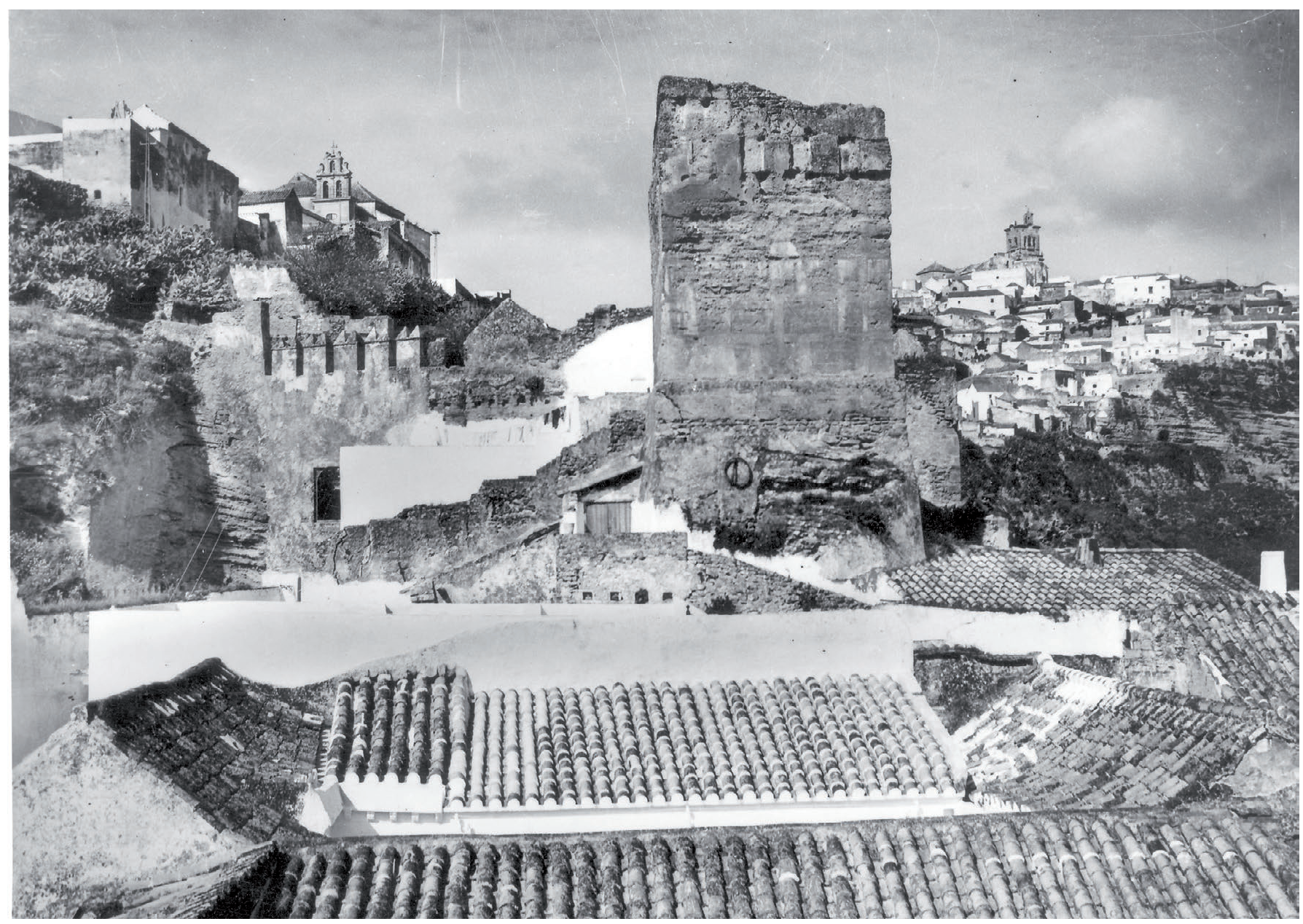

Fig. 4. Fotografía de la torre albarrana situada en las inmediaciones del Arco de Matrera, realizada por José María de las Cuevas Olivares en la década de 1920. En ella se pueden apreciar los entalles realizados en "la peña" de Arcos de la Frontera hasta conformar un volumen troncopiramidal en la cimentación de esta torre, que de esta manera se vio realzada en altura

su término bajo la jurisdicción de Sevilla en 1338, manteniéndose así hasta $1401^{27}$.

Durante esta época, una vez extinguida la amenaza meriní, se acomete un exitoso proceso repoblador concediéndose para ello franquicias jurídicas, fiscales y militares $^{28}$. Por cuanto a nosotros más nos interesa, sabemos que a finales del siglo XIV, concretamente en 1380 y en 1394 , se llevan a cabo reformas en el castillo y la cerca ${ }^{29}$.

\footnotetext{
${ }^{27}$ Acorde con el incipiente proceso de feudalización constatado en la Baja Andalucía por estas fechas, Arcos de la Frontera fue entregada en señorío al condestable Ruy López Dávalos. Tras varios cambios en la titularidad de dicho señorío, los Ponce de León se harán con el mismo en 1442. Sánchez 2003: pp. 204-205.

${ }^{28}$ Sánchez 2003: p. 204.

${ }^{29}$ En 1394, el cabildo sevillano concedía a Arcos de la Frontera la siguiente merced para arreglo de muros y aumento de vigías: "La villa de Arcos que está muy mal poblada e los muros de ella, en algunos lugares derribados y asolados, e las dichas treinta velas que nos mandamos pagar eran muy pocas y do ellas no se podía velar ni guardar la nuestra dicha villa como complía a servicio de Dios e del dicho Señor Rey y nuestro"; Pérez Regordán 2002: vol. I, p. 44.
}

En la siguiente centuria se produce una continua mejora de las condiciones de vida, a la par que la iniciativa bélica pasa a manos castellanas. En este contexto se acomete una nueva y gran reforma en las murallas y en el castillo en $1430^{30}$. Aunque la descripción que nos proporciona esta fuente es bastante detallada, nos parece significativa la ausencia de menciones a una puerta a la que llegase el camino de Matrera, así como la referencia a la Torre de la Traición, que el cronista local Mancheño y Olivares identificaba con la torre albarrana conservada en este frente sureste de la muralla (Fig. 4): "Item está caída e derribada la torre que diz de la Traición desde la bóveda que corre a la iglesia de San Juán”31.

\footnotetext{
${ }^{30}$ Mancheño 2002: vol. I, pp. 89-91.

${ }_{31}$ Mancheño 2002: vol. I, p. 90. La antigua iglesia de San Juan de Letrán, hoy convento de San Agustín, se encuentra junto al precipicio sur de Arcos de la Frontera - "peña nueva"- en una zona del casco histórico opuesta al actual Arco de Matrera.
} 
Aunque pueda resultar paradójico tratándose de una fase más reciente, la aportación de los testimonios escritos de época moderna sobre la cerca no ha resultado tan importante como cabría esperar, debido a la desaparición de gran parte del corpus documental del municipio en $1593^{32}$.

El primer aporte que recogemos durante esta etapa lo hacemos no sin cierta cautela, ya que se emite más de un siglo después, y nos lo transmite, sin referir la procedencia, el historiador local Gamaza y Romero de Aragón. Según el mismo, en 1522 la Puerta de Matrera aún tenía alcaide, cargo que por entonces ya debía de ser más honorífico y prestigioso que real ${ }^{33}$.

Contamos con alguna información que merece algo más de crédito, proveniente fundamentalmente de archivos sevillanos. Por ejemplo sabemos que en 1544 las murallas aún se seguían reparando ${ }^{34}$, aunque un siglo y medio después la situación había cambiado drásticamente, tal como nos informa en 1691 el historiador general de la Orden de la Merced: “... es la ciudad de Arcos de las más antiguas de España (...) y las murallas y torres que la ciñen arruinadas ya por el tiempo, y dejadas de reparar por el natural descuido de los Españoles que con la larga paz no se acuerdan de los daños que trae consigo la guerra, con quien ni las ciudades más fuertes y muradas están seguras..."35.

Los efectos del gran terremoto de Lisboa de 1755 se hicieron sentir de manera notable en la villa, una circunstancia ante la cual las murallas no debieron ser ajenas $^{36}$.

En el siglo XIX contamos con dos descripciones de la cerca: una bastante detallada de Mancheño y Olivares $^{37}$ y otra de Madoz Ibáñez ${ }^{38}$. En ambos casos se relacionan las tres puertas aún existentes (Carmona, Jerez de la Frontera y Matrera), resultando extraña la no mención, sobre todo por parte de Mancheño y Olivares, de la Puerta del Cómpeta.

\footnotetext{
32 Mancheño 2002: vol. I, p. 152. Por otra parte tuvimos noticia de la celebración de unas jornadas sobre Historia Moderna de Arcos anteriores al 2003, aunque parece que las actas de las mismas no llegaron nunca a publicarse.

33 Gamaza 1771: p. 29. Su Descripción de Arcos está plagada de relatos poco verosímiles, de lo que es buena prueba el desmesurado número de 50 que nos proporciona para los primeros caballeros sevillanos que repueblan Arcos tras la conquista, cuando en realidad no fueron más que ocho o nueve; Sánchez 2003: pp. 196-200.

34 Mancheño 2002: vol. I, p. 173.

35 Mancheño 2002: vol. I, p. 138.

36 Esta circunstancia se aprecia perfectamente en la basílica de Santa María de la Asunción, en especial con el contrafuerte que se adosó a su alzado norte, que cuenta con documento epigráfico.

37 Mancheño 2002: vol. I, pp. 43-44.

38 Madoz 1846-50: p. 483.
}

\section{DESCRI PCIÓN DE LAS DOS ZONAS DE INTERVENCIÓN Y PROCESO DE TRABAJ $O$}

El levantamiento fotogramétrico ha tenido por objeto el tramo de muralla conservado que cierra el núcleo histórico de Arcos de la Frontera por el sureste ${ }^{39}$, aunque la intervención arqueológica se ha centrado en los dos inmuebles situados en los extremos de dicha cerca, los cuales se adosan a la misma por su cara interna. La zonificación se ha realizado atendiendo a las áreas excavadas en estas dos viviendas.

\subsection{Zona 1. Puerta del Cómpeta y casa no 20 de la calle Torres}

La zona 1 (Fig. 5) se corresponde con una torre-puerta medieval en recodo simple, a la cual se adosa una vivienda en fechas posteriores. Al inicio de la intervención, y ante la inexistencia o desconocimiento del nombre real de la puerta por parte de los propios arcenses, decidimos referirla como "del Cómpeta” en alusión al barrio en el que se ubica.

Esta puerta en recodo presenta fábrica pétrea y es de modestas dimensiones, de lo cual dan buena prueba los $11 \mathrm{~m}^{2}$ de superficie que posee. La portada está compuesta por un arco de ladrillo de medio punto tendente a la forma de herradura (Fig. 3, arriba izquierda), con 2,52 $\mathrm{m}$ de luz. Actualmente este vano se encuentra cegado por un aparejo constituido por fragmentos de piedra arenisca y ladrillo tomados con un mortero pobre, accediéndose al interior por una puerta metálica. Una vez dentro, la torre se compone de dos estancias delimitadas por un arco diafragma. Un segundo arco de descarga se emplaza una vez efectuado el recodo, tras el cual debió ubicarse la puerta que daría acceso a la ciudad. Estos dos arcos, ambos con roscas de ladrillo y jambas que alternan este material con la piedra, soportan sendas bóvedas de cañón, construidas mediante lajas de arenisca. Hacia la cara de la puerta que se ofrecería a la ciudad, se adosa un muro con una nueva entrada correspondiente a una vivienda.

Este inmueble de la calle Torres $\mathrm{n}^{0} 20$ constituye prácticamente un rectángulo en cuyo extremo suroeste, a modo de apéndice, se encuentra la puerta en recodo. La vivienda cuenta con patio y siete estancias en su planta baja, presentando la particularidad una de ellas —a la cual se accede desde el patio- de que es el acceso a un

\footnotetext{
39 Dicho frente murado, que tiene una longitud de $136 \mathrm{~m}$, cuenta aún con 6 torres, si bien podría haber tenido inicialmente otras dos más.
} 


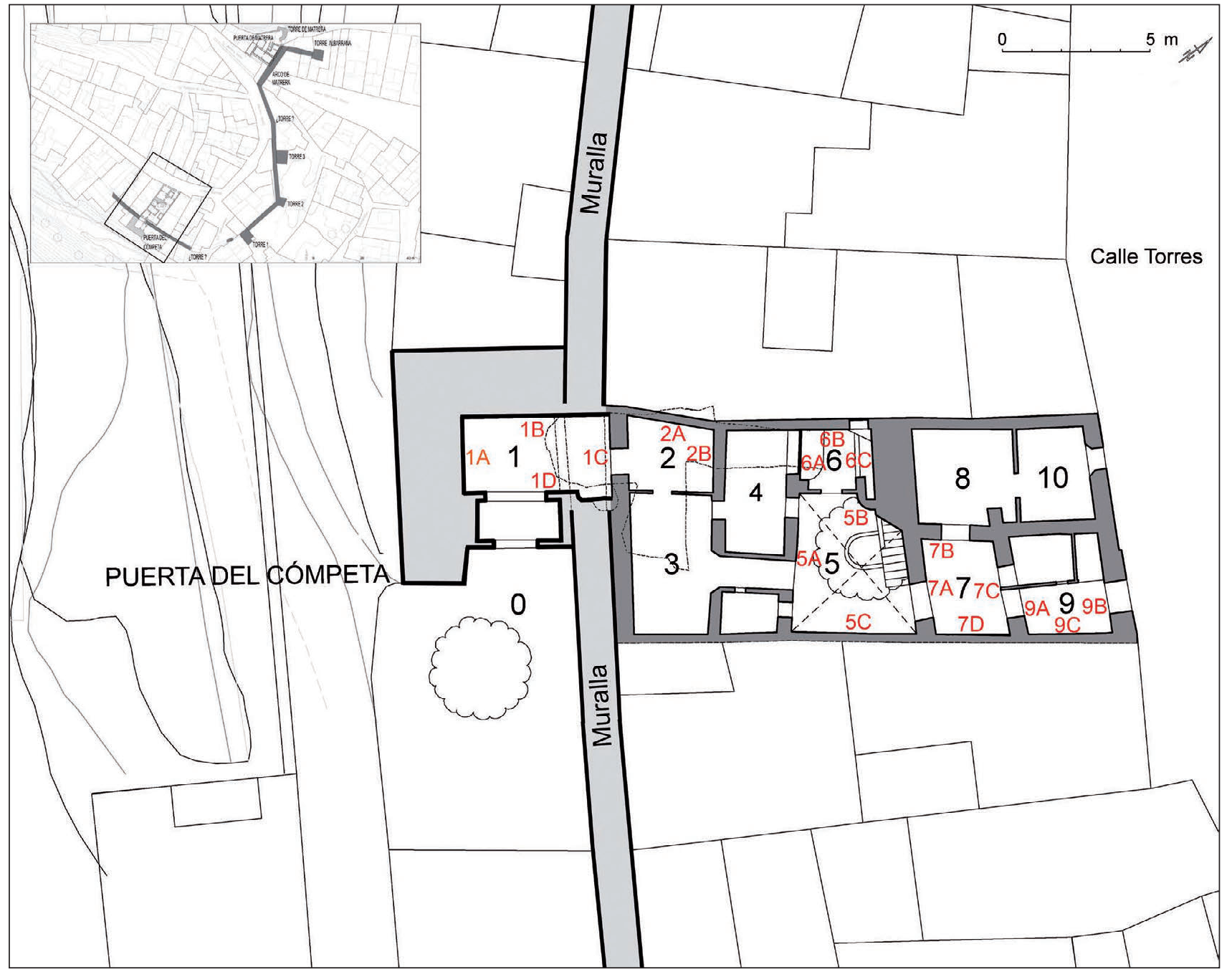

Fig. 5. Zona 1. Emplazamiento de la Puerta del Cómpeta y planta baja de la casa situada en la calle Torres no 20 , adosada por el sureste a la muralla y a dicha puerta. Numeración de sectores (en negro) y de los muros (en rojo) para la asignación de unidades estratigráficas paramentales

aljibe que se encuentra soterrado en el frente oeste de la casa.

\subsection{Zona 2. Arco de Matrera (calle Matrera Arriba no 5)}

La intervención en esta segunda zona (Fig. 6) se ha desarrollado sobre el inmueble sito en calle Matrera Arriba $\mathrm{n}^{0} 5$. Se trata de una casa que se adosa intramuros a la cerca medieval, en el arranque de la misma junto al precipicio formado por el río Guadalete. Por otra parte la vivienda es colindante con el Arco de Matrera, un paso recto a través de la cerca sobre el que se encuentra un camarín que acoge una imagen de la Virgen del Pilar. Este arco monumental permite el tránsito de vehículos desde el centro histórico de la población al Barrio Bajo, ubicado extramuros.
El solar, que cuenta con un área de $155 \mathrm{~m}^{2}$, se asienta sobre "la peña" y limita al norte con los cortados que caen hacia el río. La casa cuenta con cinco habitaciones más un patio y en la actualidad presenta dos accesos: desde la calle Matrera Arriba y desde la calle Cardenal Espínola, que es un callejón ciego que discurre paralelo al precipicio. Este segundo acceso -referido en el texto como paso de la calle Cardenal Espínola (Fig. 3, abajo) - consta en nuestros días de una puerta adintelada, engrosada por un arco de medio punto con rosca de ladrillo. Está flanqueado por un muro que, a la manera de una coracha, se encuentra unido a una torre albarrana de factura claramente medieval.

Junto a la puerta, en esta misma fachada de la calle Cardenal Espínola, hallamos otra torre (a la que nos 


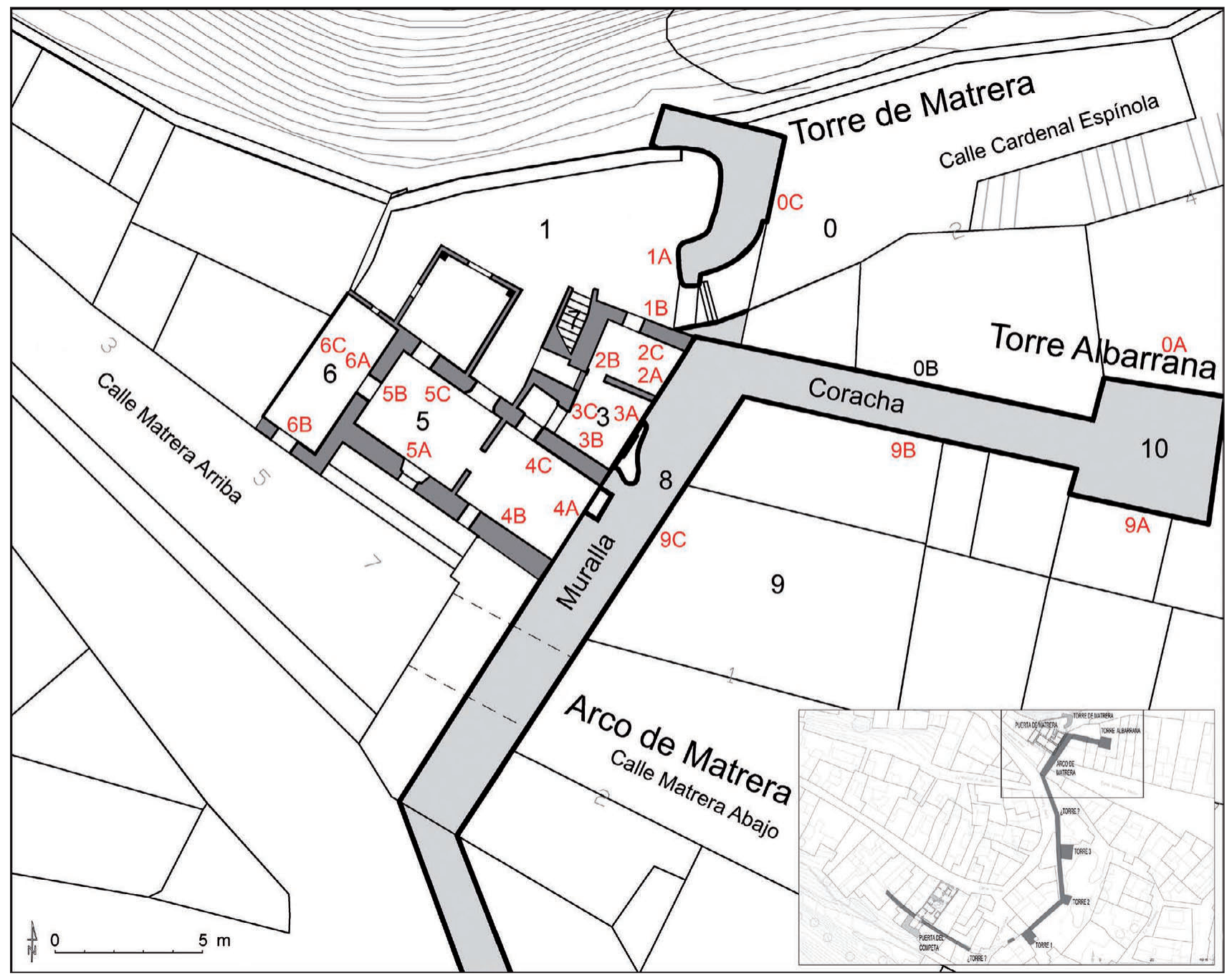

Fig. 6. Zona 2. Restos de la muralla conservados en torno del Arco de Matrera y planta baja de la casa situada en la calle Matrera Arriba no 5, adosada por el oeste a la muralla entre el Arco y la Torre de Matrera. Numeración de sectores (en negro) y de los muros (en rojo) para la asignación de unidades estratigráficas paramentales

referiremos como de Matrera), parcialmente desaparecida hacia el patio del inmueble aunque claramente apreciable desde el exterior, ya que se encuentra restaurada. No obstante, desde el interior sí que se intuye el alma de dicha torre, compuesto de tierra y piedras sobre zócalo pétreo. Precisamente en la cota desde la que arranca este alzado terroso existe un pseudo-adar$\mathrm{ve}^{40}$ estanco sobre la puerta de la calle (Fig. 7).

Desde el patio se puede subir a la azotea, y desde ésta a su vez acceder a la torre albarrana a través de la coracha, así como transitar unos pocos metros por el camino de ronda de la propia muralla, aunque éste

40 No se trata de un verdadero camino de ronda situado en lo alto de una muralla y detrás de las almenas, pues realmente está incomunicado y se encuentra más de 2 m por debajo del adarve de la muralla, así como del de la coracha, con los que no tiene comunicación. último se encuentra tapiado debido a la presencia del camarín con la imagen mariana.

Debemos señalar un singular fenómeno documentado en Arcos de la Frontera, consistente en una serie de desmontes practicados en el terreno natural a lo largo de la historia. Asociado a la expansión del tejido urbano y motivado por el deseo de suavizar la topografía y hacer las calles más accesibles, se han venido produciendo rebajes en algunas zonas de "la peña", cuyo componente fundamental es una arenisca dúctil y fácilmente erosionable. Estos rebajes son bien palpables en el casco histórico del municipio, donde con frecuencia se aprecia un considerable desnivel entre las cotas de las actuales calles y los umbrales de ciertas viviendas. Para el estudio de esta zona 2 y, en general, de los aledaños del Arco de Matrera (Fig. 4), esta circunstancia ha resultado fundamental. 


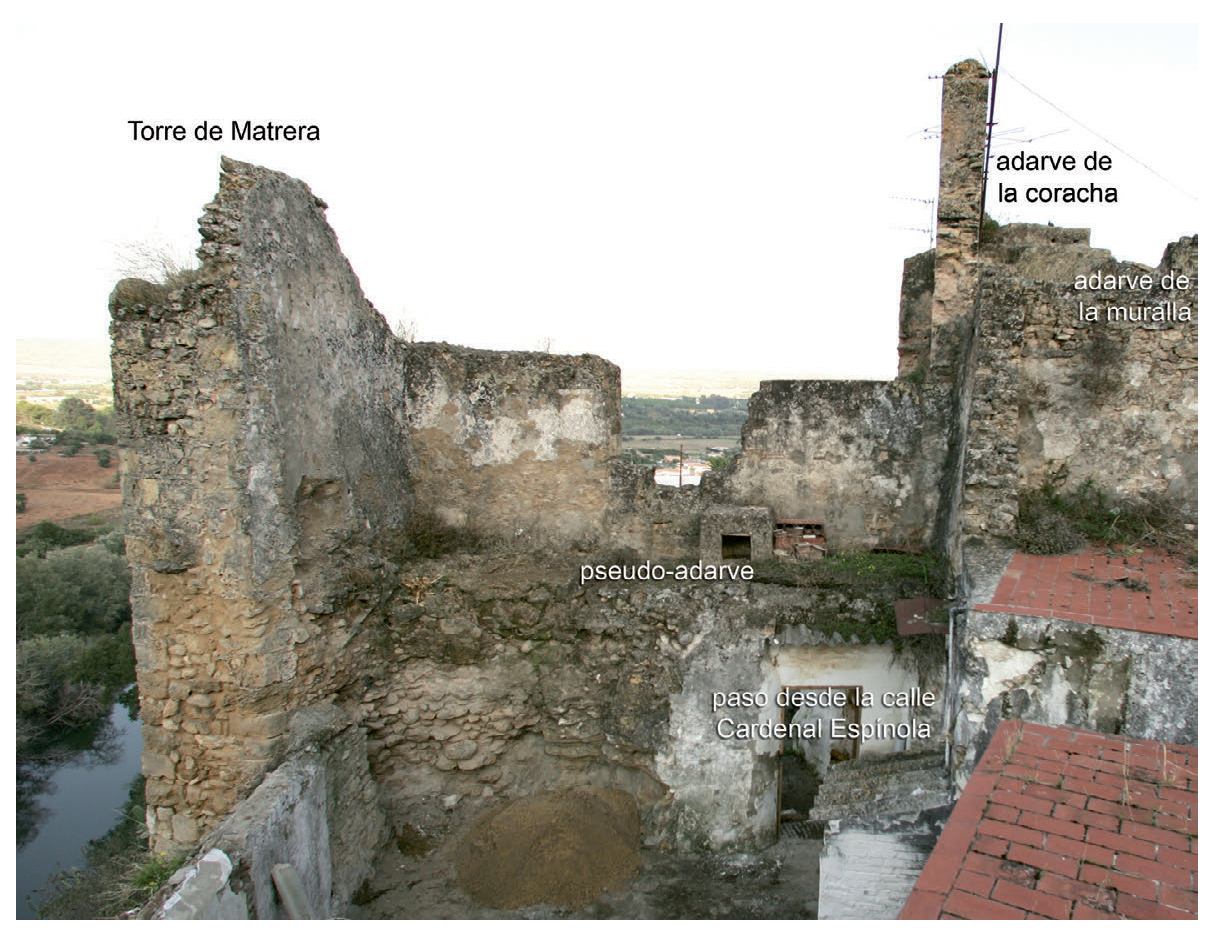

Fig. 7. Zona 2. Estructuras conservadas en el extremo septentrional de la muralla sureste de Arcos de la Frontera (sector 1, muro A). Vista desde la terraza de la vivienda situada en la calle Matrera Arriba o 5

\subsection{Proceso de trabajo}

El sistema de trabajo adoptado no ha variado sustancialmente del que se viene aplicando a edificios históricos en proceso de rehabilitación ${ }^{41}$. En cuanto al análisis tipológico murario, nos ha parecido oportuno seguir la sistematización para fábricas de tapial en Andalucía Occidental establecida por Graciani García ${ }^{42}$. Las dos zonas de trabajo se han dividido en sectores que han sido numerados atendiendo fundamentalmente a la propia compartimentación de los inmuebles. Por otra parte a los muros se les ha asignado una letra a partir de la A y siguiendo un sentido dextrógiro en cada sector. De este modo 5A aludiría al muro A en el sector 5 .

En la zona 1, la casa junto a la Puerta del Cómpeta ha sido dividida en 10 sectores de trabajo y uno más correspondiente a un aljibe subterráneo (Figs. 1 abajo y 5). Mientras que en esta zona solo se ha excavado el interior de la puerta en recodo, la intervención muraria, aparte del interior de la torre, se ha hecho extensiva a buena parte del inmueble, donde se han practicado once sondeos parietales. Finalmente, y ante la carencia de cronologías absolutas para la casa, decidimos efectuar un pequeño corte en el pavimento del aljibe de cara a obtener materiales procedentes de un depósito sellado.

La intervención arqueológica en la zona 2 (Figs. 1 abajo y 6) ha supuesto el picado completo de los paramentos

\footnotetext{
41 Tabales 2000: pp. 35-74; Tabales 2002.

42 Graciani 2009: pp. 111-140.
}

del inmueble y de la cara interna de la Torre de Matrera, así como el planteamiento de cinco catas murarias en la azotea, el adarve de la cerca y la coracha. Asimismo, en subsuelo se han practicado tres sondeos que han demostrado una potencia mínima de los depósitos arqueológicos. Toda esta zona 2 de intervención se ha dividido en otros 10 sectores que comprenden las habitaciones de la casa, el adarve de la muralla junto al camarín, la coracha y la torre albarrana.

\section{ANÁLI SI S ESTRATI GRÁFI CO}

El análisis nos ha permitido distinguir, al menos, ocho procesos edificatorios o subfases, que agrupamos a su vez en tres grandes ciclos históricos o fases (andalusí, bajomedieval y moderna).

\begin{tabular}{|l|l|}
\hline FASE & SUBFASES \\
\hline Andalusí & $1,2,3,4$ \\
\hline Bajomedieval & 5 \\
\hline Moderna & $6,7,8$ \\
\hline
\end{tabular}

\subsection{Fase Andalusí}

A esta primera etapa de la evolución constructiva pertenece la fundación del tramo sureste de la muralla de Arcos de la Frontera con las seis torres conservadas, la Puerta del Cómpeta, la torre albarrana y la Torre de Matrera. Dentro de ella distinguimos cuatro subfases que localizamos principalmente en la zona 2 . 


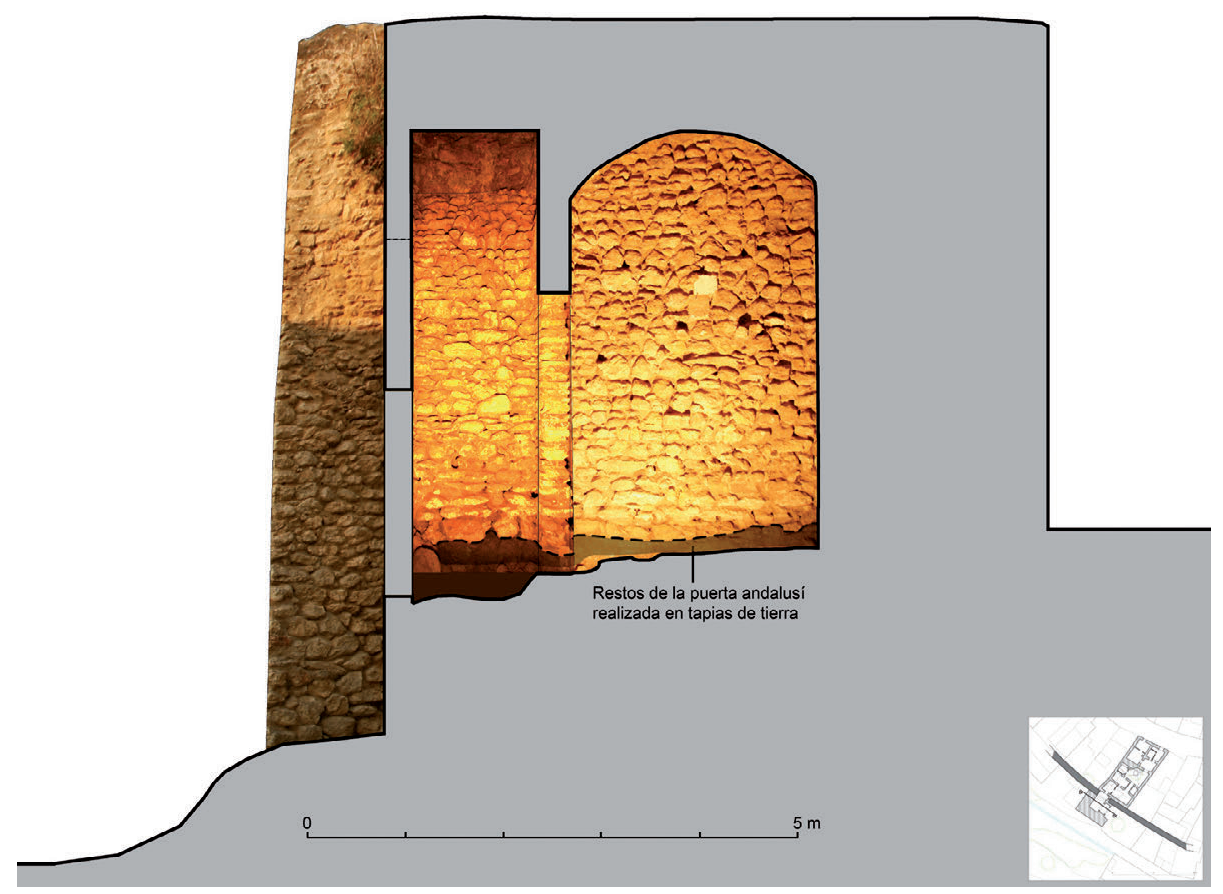

Fig. 8. Zona 1. Restos andalusíes conservados en la Puerta del Cómpeta (sector 1, muro A)

Durante esta fase existe un claro predominio del tapial con un uso puntual del ladrillo. Asimismo podemos hablar de una evolución tecnológica, constatada en el enriquecimiento gradual de los encofrados con cal en detrimento de la tierra.

\subsubsection{Subfase 1}

- Zona 1: La excavación del interior de la Puerta del Cómpeta (sector 1) descubrió restos de la obra fundacional bajo la primera hilada de sillarejo de los muros. Estos restos consistían en un tosco pavimento de mortero y piedras, la zarpa de una jamba y un fragmento de enlucido de cal en la parte inferior de la misma, así como un cimiento de tierra oscura muy compactada que descansaba directamente sobre la roca natural (Fig. 8), ante lo cual podemos afirmar que en origen la puerta en recodo se edificó aprovechando la topografía existente y adaptándose a las irregularidades del terreno. La información aportada en este sentido por los materiales cerámicos es poco precisa, reduciéndose tan solo a un único borde de ataifor (Fig. 9) que proporciona una cronología post quem para la fundación de la puerta a partir de los siglos IX-XI' ${ }^{43}$.

\footnotetext{
${ }^{43}$ Los posibles paralelismos que encontramos en la Meseta (Alcalá la Vieja) parecen remitirnos a época omeya; Retuerce 1998: vol. I, p. 140, mientras que en Málaga hayamos una clara analogía, en cuanto a morfología y cromatismo, con formas datadas en época emiral; Íñiguez y Mayorga 1993: p. 123. En ámbitos geográficos más cercanos, como en Sevilla, esta forma de ataifor vidriado se adscribiría a los siglos X-XI; Huarte y Lafuente 2001: vol. 2, p. 550.
}

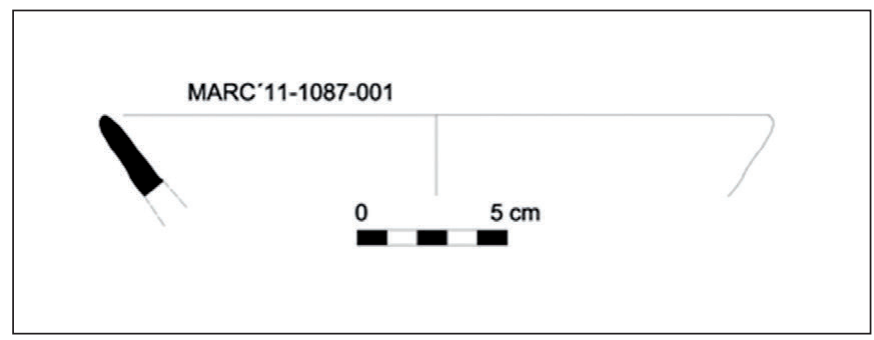

Fig. 9. Ataifor de paredes abiertas con borde recto y redondeado, melado al exterior y chocolate al interior

- Zona 2: El paramento de la muralla fundacional ha sido documentado en el interior de la casa de la calle Matrera Arriba $\mathrm{n}^{\circ} 5$ (sector 4, muro A), donde, al haber quedado protegido por tres revocos, ha aparecido prácticamente intacto. También en esta vivienda pudimos apreciar el alma de la cerca, concretamente junto al pseudo-adarve sobre el paso de la calle Cardenal Espínola (sector 1), donde la muralla se encuentra seccionada (Fig. 10). Esta muralla fue realizada en tapias o hilos de tierra oscura decantada procedente de depósitos aluviales del río Guadalete, material idéntico al constatado en la fundación de la Puerta del Cómpeta. Los hilos contienen cantos rodados sin ninguna disposición, se encuentran separados por una fina línea de cal y presentan una altura de 0,84 m, coincidentes grosso modo con dos codos rassasíes. Por otra parte algunos de los mechinales presentan la particularidad de que son dobles y tienen $5 \mathrm{~cm}$ de diámetro como término medio. 


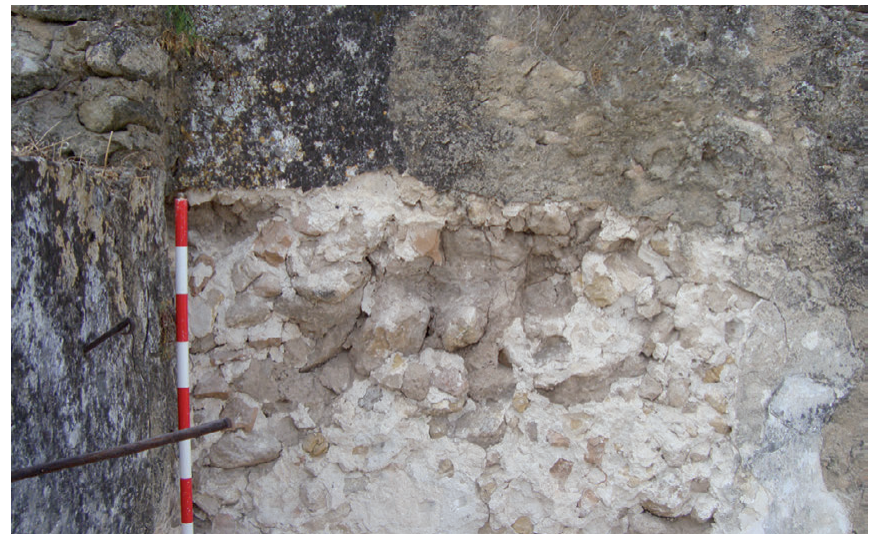

Fig. 10. Zona 2. Alma de la muralla, consolidada por revoco de cal y trozos de ladrillo, apreciable en el extremo sur del pseudo-adarve existente en la calle Matrera Arriba no 5 (sector 1, muro B)

La coracha y la torre albarrana también se inscriben en esta subfase (Fig. 11). Aunque la zona de contacto con la muralla es mínima, ambas obras son coetáneas dado que se encuentran trabadas. La información aportada por la torre albarrana (sector 10) fue fundamental, ya que sus características formales y materiales resultaban claramente apreciables. Este cubo avanzado se adosa a la coracha y su fábrica es de tapias como las descritas en el párrafo anterior. Los hilos tienen algunas características idénticas a la obra fundacional de la muralla $(0,84 \mathrm{~m}$ de altura $\mathrm{y}$ mechinales dobles) y los materiales que componen el tapial son también similares a los lugares en los que se ha podido constatar la obra fundacional de esta muralla de tierra $^{44}$. A diferencia de ellos, la albarrana muestra cintas de mortero simulando un falso despiece de sillares ${ }^{45}$.

\subsubsection{Subfase 2}

Este proceso supone la reparación de la muralla mediante encofrados de cal y arenisca, procedente de "la peña". Quizás entre ellos podría encontrarse el cuerpo inferior de la coracha (sector 0 , muro B), que es una fábrica encofrada que contiene, al menos, dos hiladas horizontales de sillarejo de arenisca tomado con mortero de cal. A pesar de que no intervinimos directamente sobre este paramento y su superficie no se encontraba limpia, las piedras escuadradas parecen disponerse a soga y tizón.

\subsubsection{Subfase 3}

- Zona 2: Es de nuevo en la torre albarrana donde documentamos esta subfase, en la que se rehicieron con

\footnotetext{
44 Tales como los restos de la muralla existentes en la casa de la calle Matrera Arriba $n^{\circ} 5$, o los que afloran junto al Camarín de la Virgen, en la Torre 1, en el muro situado junto a la Puerta del Cómpeta y en restos de las tapias de tierra conservadas como basamento de esta puerta.

45 Menéndez et al. 1994: pp. 481-511; Márquez y Gurriarán 2008: pp. 115-134.
}

ladrillo $(28 / 29 \times 14 \times 4 / 5 \mathrm{~cm})$ los merlones esquineros de la torre, suponemos que por ser los más expuestos a los agentes atmosféricos, en especial a los vientos húmedos provenientes del Océano Atlántico.

\subsubsection{Subfase 4}

- Zona 2: Siguiendo un orden ascendente en la lectura muraria de la torre albarrana, es en ésta misma y en los merlones de la muralla junto al camarín (sector 9, muro C) donde se constata esta cuarta subfase andalusí, en la que aparecen verdaderas obras de hormigón de cal. En este momento se produce el cegado de las almenas y el recrecido de la merlatura que observamos en la torre albarrana. El objetivo sería aumentar la altura del antepecho respecto a los niveles de suelo existentes en aquella época bajo los muros.

\subsubsection{Datación de la muralla: argumentación}

En cuanto a la cronología de la muralla, tenemos, por un lado, indicios que apuntarían hacia una datación pre-almohade, aunque otros elementos permitirían adscribirla a la labor constructiva desarrollada por los Unitarios en la Península Ibérica.

Las características de esta muralla andalusí de Arcos de la Frontera permitirían identificarla como una obra de módulo bajo y tapias simples o comunes, según la terminología empleada por Tabales Rodríguez y Graciani García, y que encajaría con la tipología establecida por dichos investigadores para época taifa/almorávide en la cercana ciudad de Sevilla y su territorio próximo ${ }^{46}$. La sencillez constructiva y material de la muralla (Fig. 12) — carente de basamento pétreo y con rollizos de poco diámetro por agujas, probablemente pasantes - el protagonismo de la tierra como principal componente — conjugada con piedras — y por ende, el hecho de que las obras de tapial que se vienen atribuyendo a los almohades parezcan conformarse, generalmente, mediante hormigón de $\mathrm{cal}^{47}$, apuntarían a momentos previos a la presencia de esta dinastía norteafricana en al-Andalus.

\footnotetext{
46 Graciani y Tabales 2008: p. 140. Graciani 2009: pp. 117, 130.

${ }^{47}$ La aparición de las fábricas hormigonadas parece ser un fenómeno más o menos generalizado en al-Andalus a partir del siglo XII, aunque siempre debemos mantener ciertas reservas al respecto. Recogemos algunas referencias bibliográficas de índole genérico: Gurriarán y Sáez 2002: pp. 561-626; Torres 1949: p. 52; Azuar 2004: p. 59; Márquez y Gurriarán 2008: p. 117. Otros trabajos específicos para los casos de la cerca de Sevilla serían: Valor 1991: pp. 207-208; Graciani 2009: p. 117. Para la Alcazaba de Badajoz: Torres 1941: p. 181. Para la cerca de Cáceres: Márquez y Gurriarán 2003: pp. 57-118. Para las murallas de Niebla: Pérez Macías et al. 1998: p. 349. Para el Alcázar de Jerez de la Frontera: Aguilar 2000: p. 100; Menéndez y Reyes 1987: p. 767. Asimismo este empleo de la tapia de hormigón junto con el ladrillo está documentado también en la arquitectura mardanisí, coetánea de la almohade: Navarro y Jiménez 2011: pp. 85-120.
} 

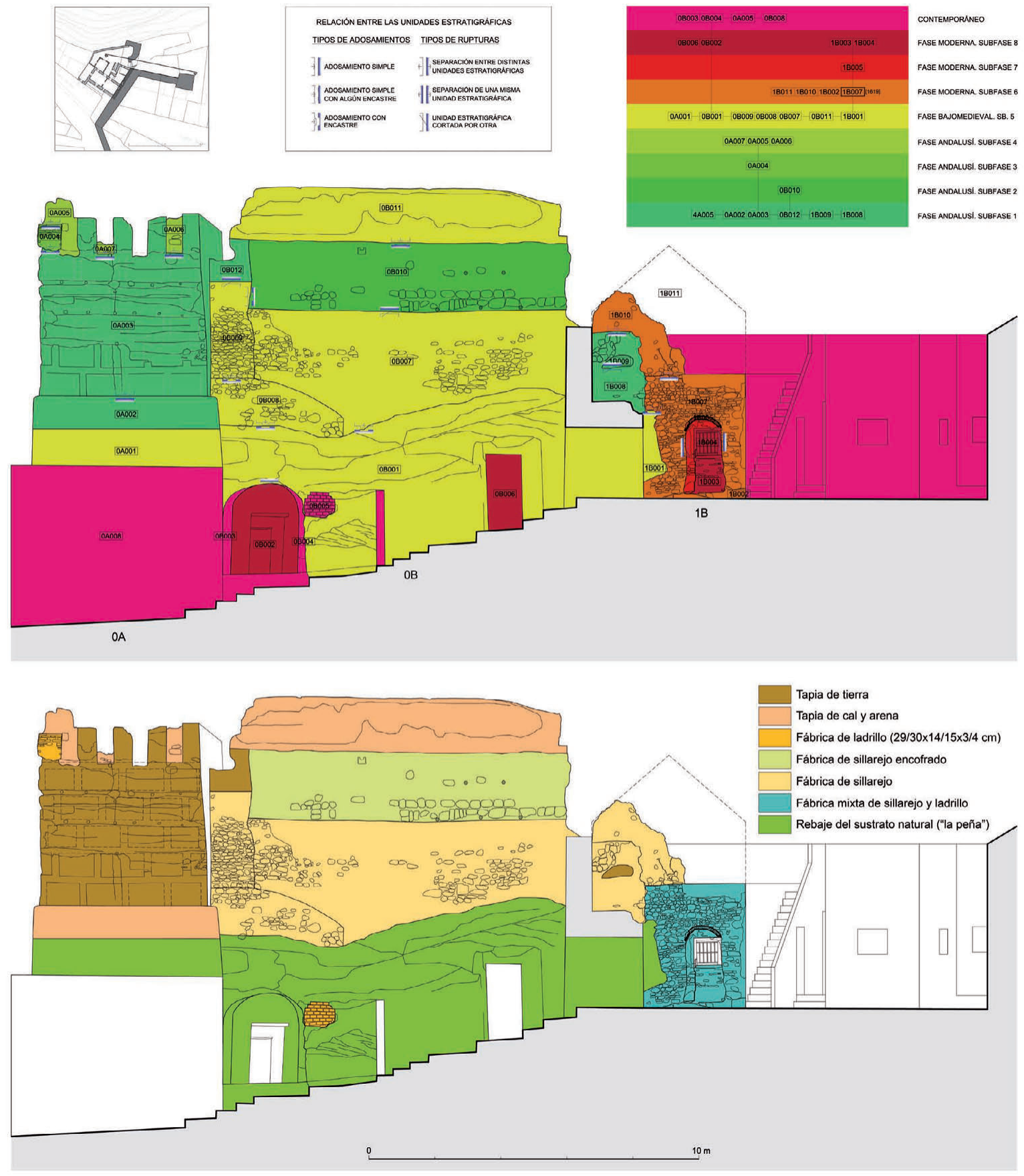

Fig. 11. Zona 2. Sección longitudinal por la calle Cardenal Espínola, con el análisis paramental y la materialidad del alzado norte de la torre Albarrana, la coracha y la vivienda de calle Matrera Arriba no 5 adosada a la muralla

Por el contrario, otras evidencias apuntarían hacia una datación almohade, como la existencia de estructuras defensivas de este período en Garb al-Andalus carentes de ladrillo y con solución de agujas dobles ${ }^{48}$.

\footnotetext{
${ }^{48}$ Como las murallas de Cáceres, donde no aparece el ladrillo; Márquez y Gurriarán 2003.
}

Mención aparte merecen la puerta en recodo situada en el barrio del Cómpeta, así como la torre albarrana y el falso despiece en sillares que ésta presenta ${ }^{49}$. Y es que

\footnotetext{
${ }_{49}$ Sobre el falso despiece de sillares, vid. nota 45. Para las torres albarranas, vid. Torres 1942b: pp. 216-220; Pavón 1999: pp. 252-277; Mora y Figueroa 1994: p. 195.
} 


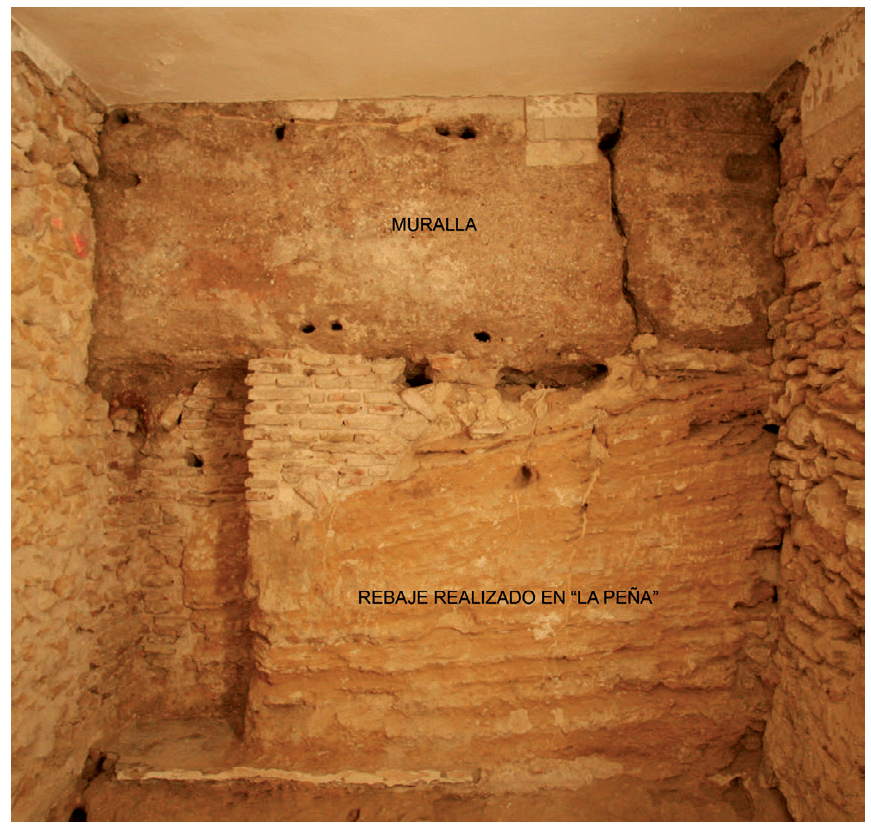

Fig. 12. Zona 2. Restos de la muralla sureste de Arcos de la Frontera aparecidos en el paramento este (muro A) del sector 4 de la casa de la calle Matrera Arriba $\mathrm{n}$ 5, con la presencia de mechinales dobles

tradicionalmente las torres albarranas, al igual que el falso despiece en sillares, se han asociado a la edilicia de los Unitarios, aunque el caso más antiguo documentado por el momento en al-Andalus parece encontrarse en Calatayud ${ }^{50}$. Esta premisa es aplicable también a la puerta en recodo ${ }^{51}$, cuya cronología más temprana se ofrece en Calatrava la Vieja, fechada al igual que la torre albarrana aragonesa en el siglo IX ${ }^{52}$.

\subsection{Fase bajomedieval}

Esta etapa se caracteriza por dos importantes hechos constatados en sendas zonas de trabajo: la reconstrucción de la Puerta del Cómpeta y el gran rebaje de la roca natural documentado en la casa de la calle Matrera Arriba $\mathrm{n}^{\circ} 5$.

En cuanto a los materiales y técnicas documentados, en esta fase aparece la piedra más o menos tallada —procedente de la misma "peña" — en, al menos tres variantes distintas: sillarejo, mampostería y lajas irregulares. Asimismo el ladrillo se combina con la piedra en jambas y roscas de arcos, aunque no se abandona la tradición de la tapiería.

\footnotetext{
50 Souto 2005: pp. 88, 151.

51 Al igual que para las torres albarranas, la bibliografía básica sobre este particular recoge las obras de los siguientes autores: Torres 1960: pp. 419441; Jiménez 1972: pp. 20-40; Pavón 1999: pp. 403-408.

52 Retuerce y Hervás 1999: pp. 23-43.
}

\subsubsection{Subfase 5}

- Zona 1: La intervención demostró que, a partir del último cuarto del siglo XIV, la puerta acodada que venimos denominando del Cómpeta (sector 1) fue reconstruida prácticamente desde los cimientos y bajo unas pautas plenamente mudéjares, en un aparejo homogéneo de sillarejo y lajas de arenisca. La cronología post quem para este hecho nos las proporciona una moneda ${ }^{53}$, hallada bajo el suelo de trabajo asociado a la reforma. Asimismo se empleó el ladrillo — quizás de acarreoen la portada y arcos del interior de la puerta, donde documentamos un módulo de 26x12×4 cm.

A partir de la fábrica pétrea que presenta la Puerta del Cómpeta, tanto en los alzados como en la bóveda, podemos establecer un claro paralelismo con la Torre del Homenaje del cercano castillo de Matrera ${ }^{54}$ (Fig. 13), cuya construcción se produce a partir de $1341^{55}$.

- Zona 2: Basándonos en los materiales cerámicos exhumados, pensamos que fue a partir de la conquista del siglo XIII cuando se produjo el primer gran rebaje de "la peña" en el interior de la casa de la calle Matrera Arriba $n^{\circ} 5$, alcanzándose cotas cercanas a las actuales (Fig. 14). Sería entonces, una vez rebajada la roca por primera vez, cuando se rehace la Torre de Matrera (sector 1, muro A) con un basamento de piedra tomada con mortero y un alzado macizo de tierra, probablemente reaprovechada de la muralla andalusí. Sin embargo, nada sabemos de la configuración del espacio en aquellos momentos, pues la casa que vemos hoy se data en fechas posteriores.

En esta fase también podríamos incluir la construcción de un peto de tapias hormigonadas en la parte superior de la coracha (Fig. 11). Éstas asientan sobre doble verdugada de ladrillo de acarreo, y su paramento denota la presencia del barzón de la horma, lo que nos demuestra que este muro se hizo mediante dos encofrados continuos.

\subsection{Fase moderna}

En este período se producen dos grandes momentos constructivos que transforman notablemente la fisonomía urbana del sureste de Arcos de la Frontera.

Afortunadamente, para esta etapa los muros nos proporcionaron dos dataciones absolutas, una para cada zona de intervención, lo cual facilitó enormemente la

\footnotetext{
53 Cornado de Pedro I, que reinó en Castilla entre 1350-1369.

54 Situado en la cercana localidad de Villamartín.

55 Gutiérrez y Martínez 2003: p. 107.
} 

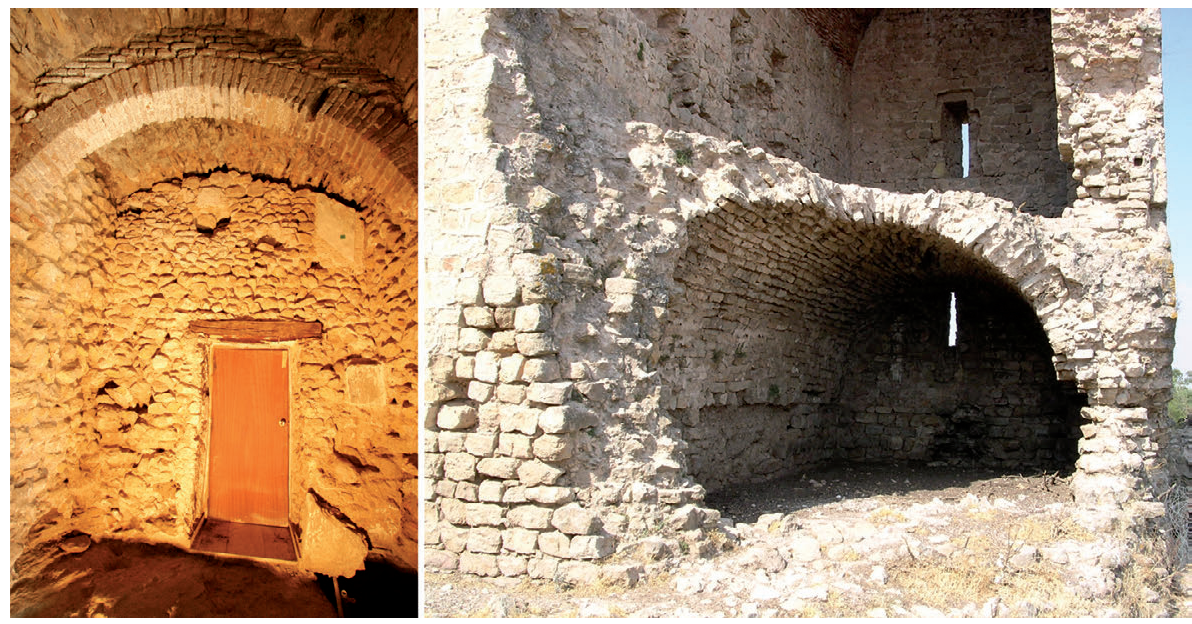

Fig. 13. (Izquierda) Interior de la Puerta del Cómpeta (zona 1, sector, muro C). (Derecha) Torre del Homenaje del castillo de Matrera, estado previo a los desperfectos sufridos como consecuencia de las lluvias del invierno de 2013 (fotografía cortesía de Alejandro Pérez Ordóñez) interpretación de la secuencia cronoestratigráfica. Podemos afirmar que los dos inmuebles objeto de nuestro estudio se datarían en esta fase, en la cual se produce también el abandono de la Puerta del Cómpeta y la ruina paulatina de la propia muralla. Durante esta etapa surgen nuevas casas que invaden zonas de la muralla, se adosan a ella y reaprovechan sus materiales constructivos, unas circunstancias que se reflejan bien en las dos zonas de intervención.

En la zona 1 constatamos hasta cinco fábricas diferentes asociadas a procesos de construcción-destrucción, en los cuales se redefinen espacios y aparecen nuevos cuerpos en altura (Fig. 15). En la zona 2 se produce un nuevo rebaje de "la peña", se amortiza definitivamente el adarve de la muralla, debido a la presencia del camarín con la imagen de la Virgen del Pilar, y se produce el crecimiento en altura de la casa de la calle Matrera Arriba $n^{\circ} 5$ (Fig. 16).

Referente a los materiales empleados, podemos afirmar que se mantiene en ámbitos domésticos el uso de la arenisca procedente de "la peña" en diversas variantes (mampuestos de piedra, relleno de las tapias

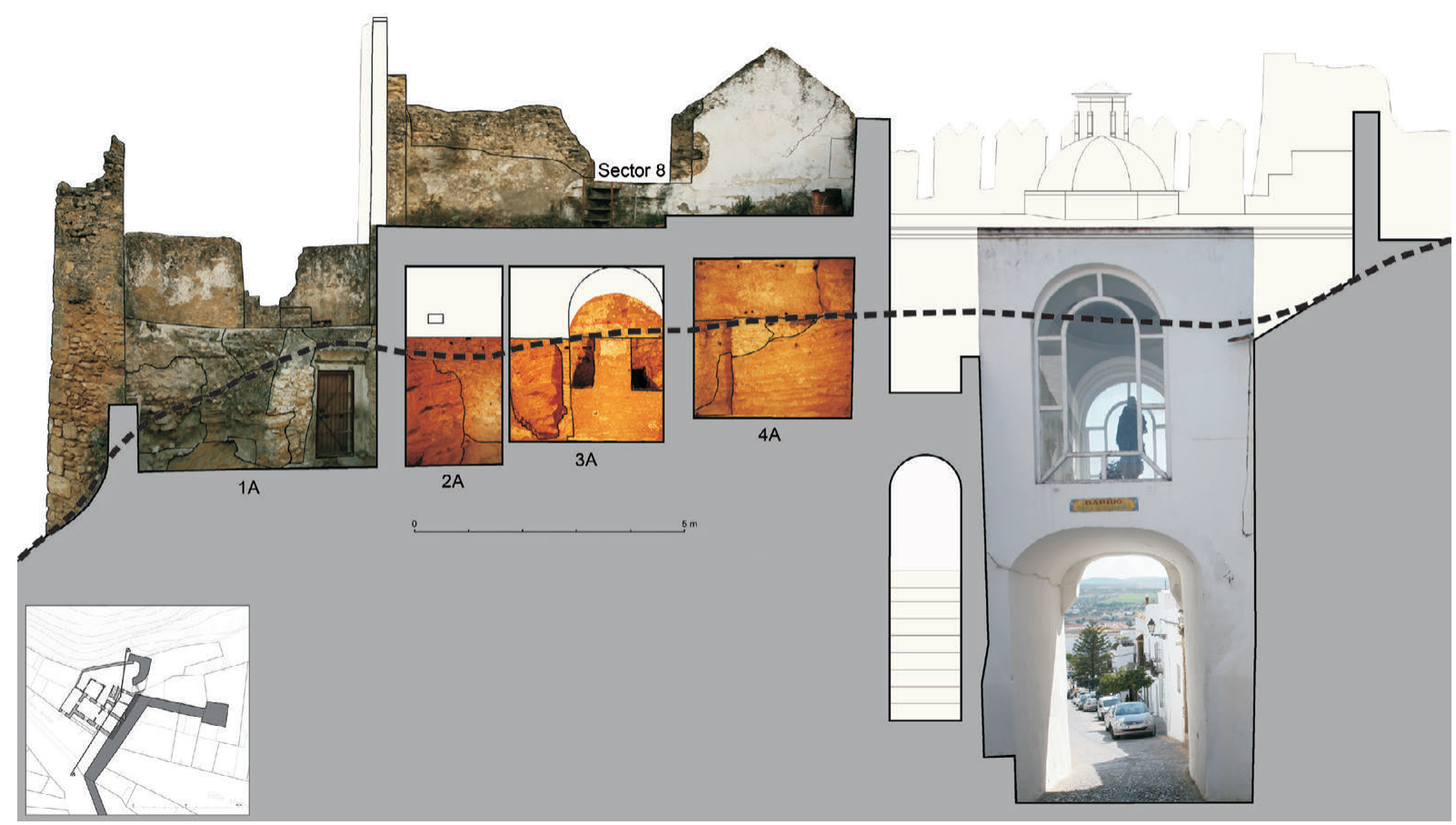

Fig. 14. Zona 2. Cara oeste de la muralla entre la Torre de Matrera (izquierda) y el Arco de Matrera (derecha). En el mismo se observan restos de la cota original de "la peña" de Arcos de la Frontera sobre la que asentaría la muralla medieval de tapias de tierra, de la que quedan indicios y restos conservados en este alzado. Se ha marcado la línea que presumiblemente definiría el terreno natural en el momento en el que se construyó la muralla sobre ella 

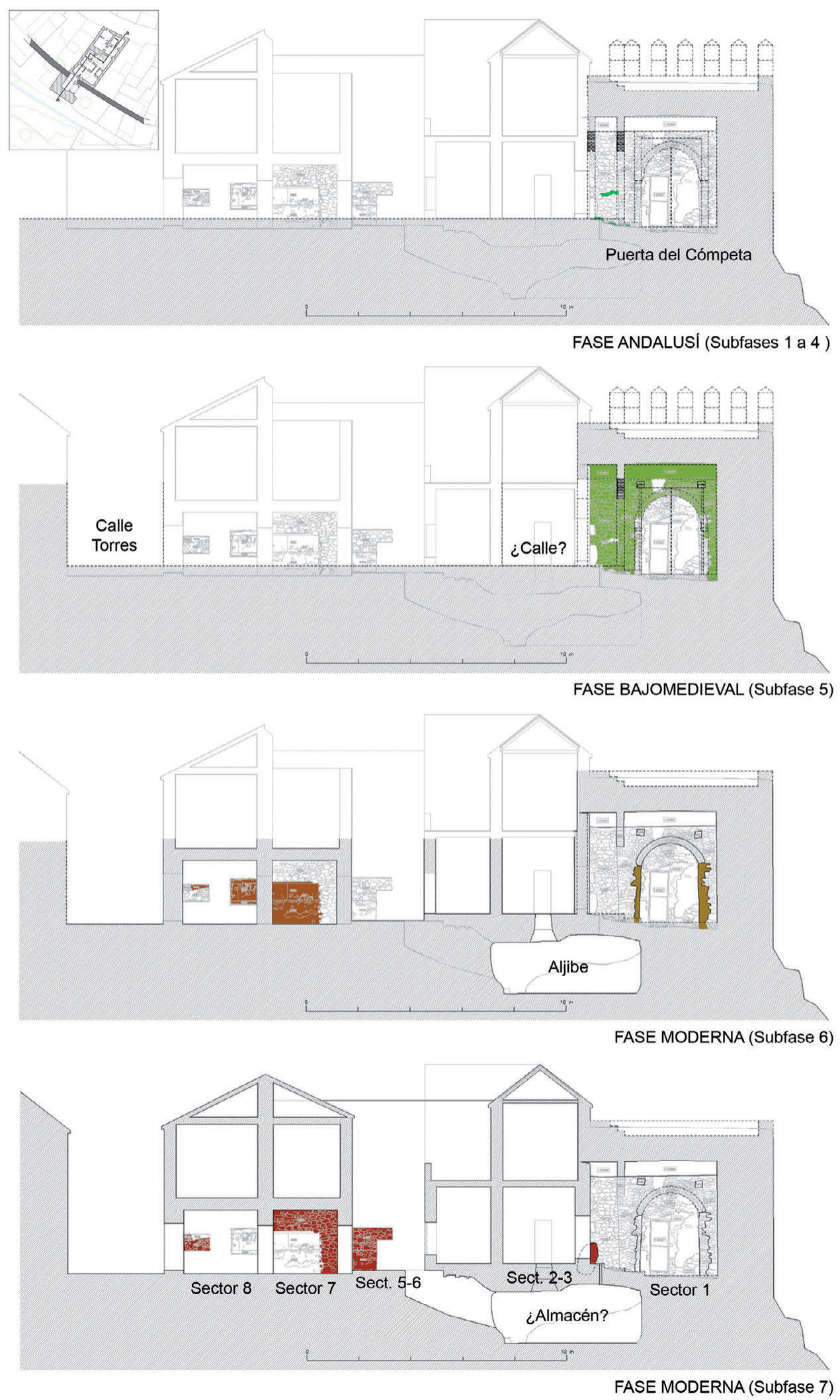

Fig. 15. Zona 1. Estudio evolutivo de la Puerta del Cómpeta y de la vivienda adosada a la misma por el norte 


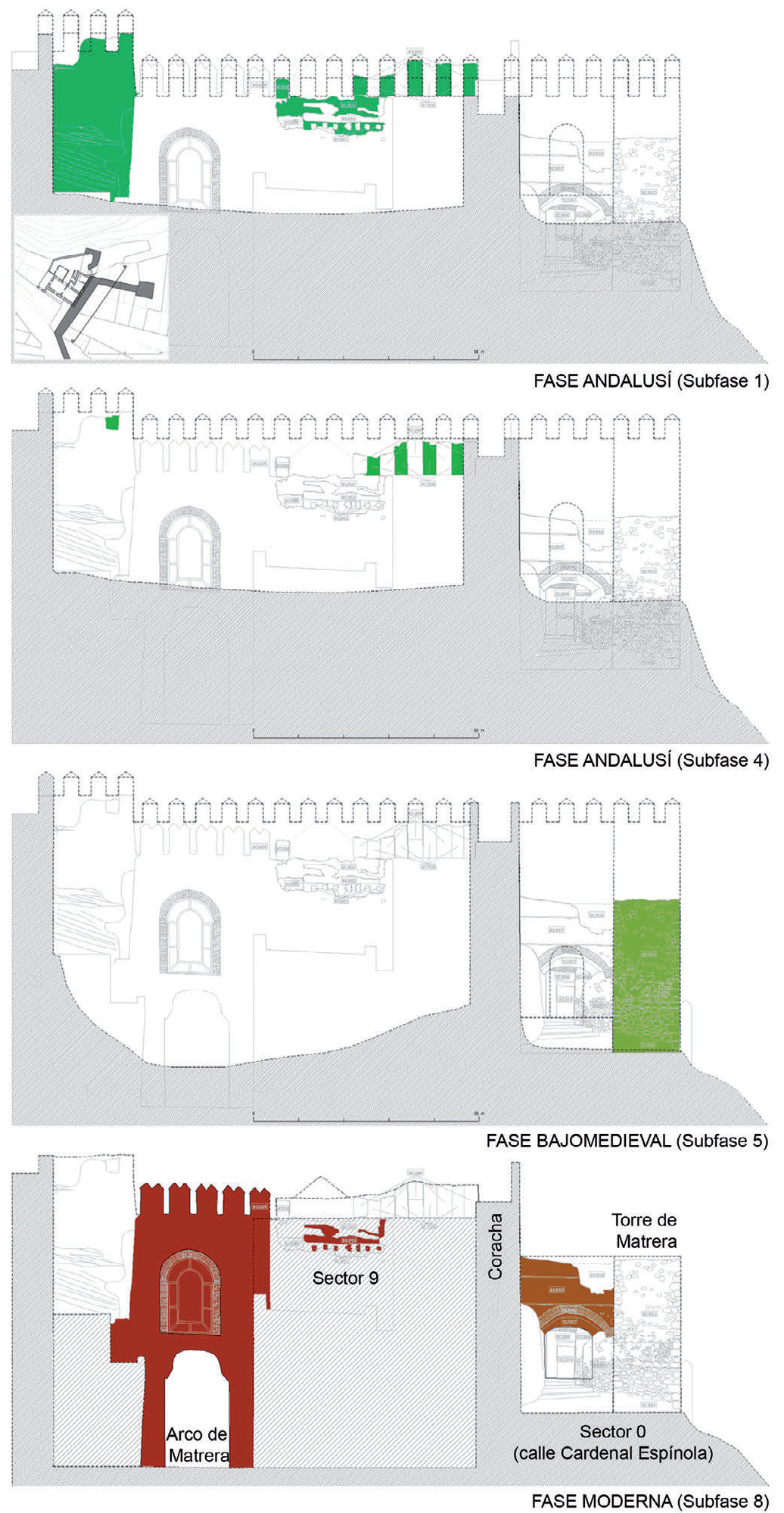

Fig. 16. Zona 2. Estudio evolutivo del lienzo murario existente en torno al actual Arco de Matrera en su alzado este

o conglomerante para morteros y revestimientos). Sin embargo, lo más destacable es el mayor protagonismo del ladrillo, que, aparte de en vanos y jambas, aparece en estos momentos conformando aparejos mixtos con fábricas encofradas, ya sean de tierra o de mampostería.

\subsubsection{Subfase 6}

- Zona 1: La moneda ${ }^{56}$ aparecida en un enfoscado del interior de la Puerta del Cómpeta, nos indica que, en

\footnotetext{
564 maravedísrecortadosdeFelipe III, sinfecha, acuñados enlacecadeGranada.
} 
algún momento a partir de 1598, la torre ya funcionaba como vivienda (Fig. 15), contando con una compartimentación tripartita. Pensamos que este momento hubo de ser tardío, ya que durante los siglos XVI y al menos gran parte del XVII, la puerta estuvo abandonada, o al menos no tuvo un uso doméstico claramente definido, lo cual se justifica por la poca cantidad de cerámica moderna aparecida en la excavación del interior.

Este abandono explicaría la presencia del alzado postizo (sector 2, muro C) (Fig. 13, izquierda) que actualmente separa la propia puerta en recodo de la vivienda de la calle Torres $n^{\circ} 20$, cuya existencia supone también la destrucción de la muralla en esta zona. Este alzado presenta un notable interés porque refleja perfectamente el reaprovechamiento de los materiales de la cerca, ya que es una obra de tapial que contiene tierra negra y piedras de considerable tamaño, reparadas por alzados de mampostería irregular tomada con mortero de arenisca y poca cal.

A partir de la información ofrecida por la cerámica hallada bajo el pavimento del aljibe, podemos sostener que la casa de la calle Torres 20 se erige en algún momento del siglo XVI ${ }^{57}$. A pesar de las reparaciones hemos documentado la fábrica de las medianeras de la casa, formadas por tapias sobre basamento pétreo, compuestas por tierra y algo de grava. A estas medianeras se encastran en un primer momento los muros transversales $(6 \mathrm{~A}, 6 \mathrm{C}, 7 \mathrm{~A}$ y $7 \mathrm{C})$ que definen los sectores $4,5,6,7$ y 9 .

Especial importancia presentan los sectores 2 y 3 , que suponen el nexo entre la vivienda y la puerta en recodo. Aunque la intervención no lo ha aclarado completamente debido a que no se ha excavado el interior de la casa de la calle Torres n ${ }^{\circ}$ 20, barajamos la hipótesis de que en época bajomedieval existiese una calle paralela a la muralla por su cara interna, preservando de ese modo su finalidad defensiva. Si aceptamos esta propuesta, la cual no es desmentida por los contactos murarios, esta calle medieval habría quedado fosilizada en los sectores 2 y 3 (Figs. 5 y 15 centro).

- Zona 2: La vivienda intervenida en la calle Matrera Arriba $\mathrm{n}^{\circ} 5$ se data a partir de inicios del siglo XVII. Esta propuesta la basamos en la moneda ${ }^{58}$ aparecida en el interior del muro (1B) en su fachada hacia el patio, que podría adscribirse a esta subfase.

\footnotetext{
${ }^{57}$ El único fósil director es un pequeño borde de loza con decoración en azul sobre blanco, que se podría adscribir a la producción trianera conocida como azul lineal; Fournier y Casado 2007: pp. 221-222.

584 maravedís recortados de Felipe III. Ceca de Cuenca, 1619.
}

Al contrario que la casa de la calle Torres $\mathrm{n}^{\circ} 20$, esta vivienda, cuyos enfoscados fueron completamente retirados, presenta pocas reparaciones y bastante homogeneidad en cuanto a sus fábricas. Es por ello por lo que consideramos que la actividad edilicia se concentró en un arco cronológico no excesivamente amplio, que comprendería los siglos XVII y XVIII, a pesar de lo cual los contactos murarios nos permiten distinguir tres subfases. Pertenecientes a la primera, contamos con el muro perimetral 4B-5A que linda con la calle, de algo más de grosor que el resto, y formado por un vasto aparejo de piedra arenisca sin ninguna disposición ni regularidad.

\subsubsection{Subfase 7}

- Zona 1: Aparición de nuevos vanos transversales adintelados, también de ladrillo ${ }^{59}$ (5A, 7A) encadenados con aparejo mixto de hiladas de ladrillo con cajones de mampostería (7A, 7B). En esta subfase se produce el cegado de un doble arco de ladrillo existente en el muro 5A-6A, motivado por la ocupación del aljibe, posibilitando la entrada al mismo mediante una rampa desarrollada bajo el arco del muro 6A (Fig. 17). Este hecho a su vez generó la apertura de un nuevo acceso al patio en la parte meridional del muro 5A. Además se constata la ruina parcial de la fábrica originaria de las medianeras y su sustitución por obra de yeso y cascajo, (documentadas en el sector 6, muro 6B). Estas acciones se concretan en el crecimiento en altura de la vivienda, a partir del cual surgen la segunda planta y la azotea (Fig. 15).

- Zona 2: A esta segunda subfase de la fase moderna sería a la que corresponden los alzados 4C-5C, $5 \mathrm{~B}-6 \mathrm{~A}$ y $6 \mathrm{~B}$, formados por aparejo mixto de tapias y piedras. Todos estos muros presentan ladrillos de módulo 30x15x4 cm. Por otra parte, en el estudio de esta vivienda ha resultado particularmente importante la comparativa de morteros, apreciando la misma argamasa sencilla formada por arenisca y cal.

\subsubsection{Subfase 8}

- Zona 2: Documentamos, por último, una tercera subfase dentro de la fase moderna, fechable probablemente hacia la segunda mitad del siglo XVIII. Vendría representada por la construcción de una bóveda de arista (Fig. 18) asociada a un vano de medio punto realizado con ladrillo (muro 3C). Esta relación estratigráfica la

\footnotetext{
59 Ladrillos con módulo 26/28x13/14x4/4,5 cm.
} 


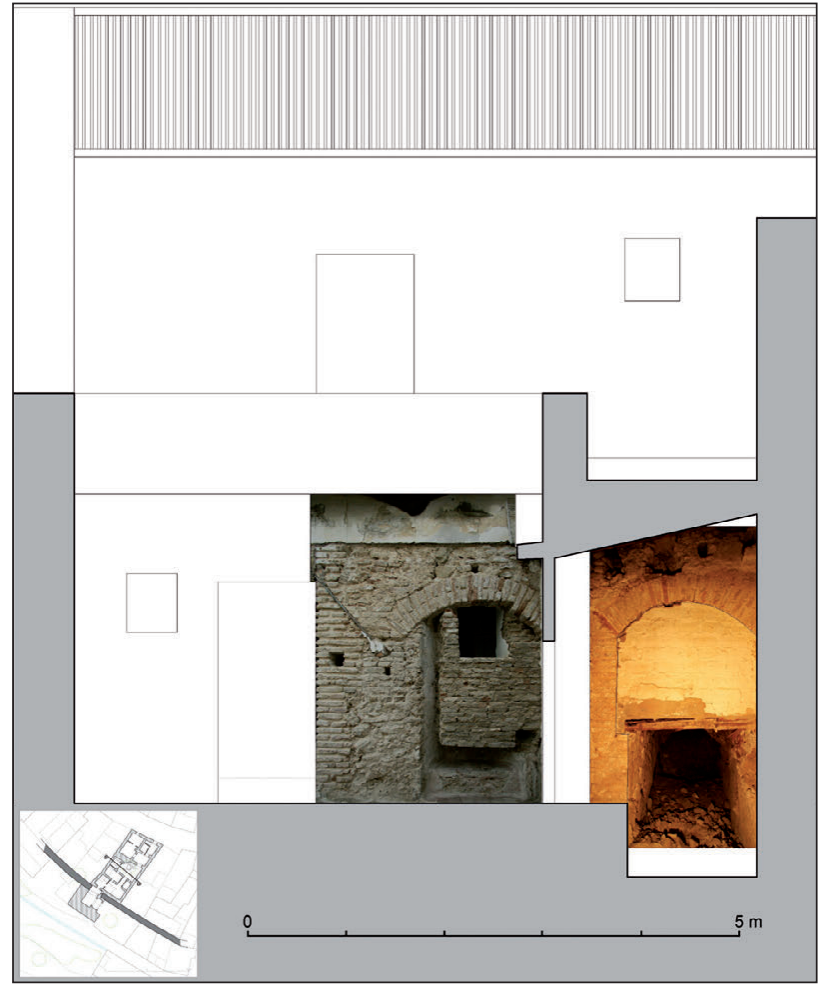

Fig. 17. Zona 1. Doble arco de ladrillo (sectores 5 y 6 , muros A). El acceso al aljibe se encuentra en la parte inferior del arco de la derecha

observamos en el sector 3, donde las tapias de arenisca $\mathrm{y}$ cal del muro 3B fueron cortadas en su parte superior para insertar los ladrillos a panderete $(30 \times 15 \times 4 \mathrm{~cm})$ que conforman la bóveda.

Este proceso constructivo de la vivienda fue inversamente proporcional a la ruina y amortización de la muralla y de la Torre de Matrera. Una enorme interfaz de destrucción, generada por el afán de obtener piedra para alzar y reparar muros, justifica la existencia del pseudo-adarve (sector 1, muro A, Fig. 7); en realidad equivale al alma de tierra de la Torre de Matrera, la destrucción de la muralla en esta zona y la consiguiente aparición de la actual portada de la calle Cardenal Espínola. El ladrillo presente en el aparejo mixto de la misma coincide con el que se encuentra en la bóveda del interior de la casa $(30 \times 15 \times 4 \mathrm{~cm})$. A su vez el mortero de la portada es el mismo que hallamos en los muros de la terraza y azotea de la casa, los cuales se corresponden con el cegado del adarve ante la presencia del camarín (sector 8, Fig. 14).

Por último, se produce un segundo rebaje de "la peña” bajo el Arco de Matrera, alcanzándose las cotas de uso que observamos actualmente en esa calle (Fig. 16).

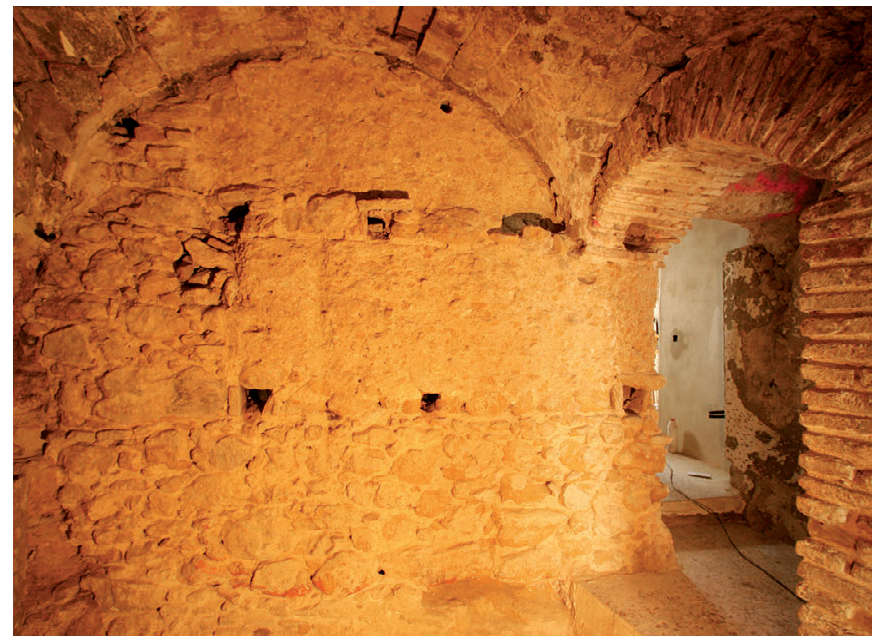

Fig. 18. Zona 2. Bóveda en el sector 3 (al frente, muro B) en la vivienda de la calle Matrera Alta no 5

\section{CONCLUSIONES}

Iniciamos este último epígrafe señalando algunos aspectos que nos han parecido importantes a la hora de tratar de comprender la evolución de las estructuras analizadas:

En primer lugar, el fenómeno local de los desmontes y rebajes efectuados en "la peña" (Figs. 4, 14 y 16), al menos, desde época medieval, lo que supone la alteración de los depósitos estratigráficos.

Por otra parte, la presencia de las usuales reparaciones de las fábricas de tierra en edificios históricos con un uso dilatado en el tiempo. Como es sabido, con bastante frecuencia la tierra fue el material elegido para construir murallas ${ }^{60}$, aunque debido a su propia naturaleza, la fábrica fundacional de muchas de estas cercas ha desaparecido, habiendo sido sustituida completa o parcialmente por fábricas más consistentes, o bien se encuentra enmascarada por revestimientos de piedra, ladrillo, etc ${ }^{61}$. Esta premisa ayudó a comprender la presencia de tierra en contextos secundarios y a explicar momentos de destrucción en los restos emergentes, ante

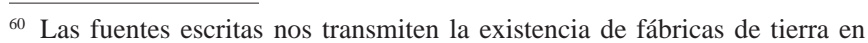
conjuntos murados y fortificados de al-Andalus durante la Edad Media. Tenemos los ejemplos de Tarifa en el siglo XII (al-Idrisi 1974: p. 165), Badajoz en el siglo IX (Lévi-Provençal y García 1950: pp. 112-113), el Alcázar de Toledo en el siglo VIII (Ibn Hayyan 2001: p. 31) y probablemente la cerca de Sevilla, construida durante la fitna del siglo XI (al-Bakri 1982: p. 33).

${ }^{61}$ Estas prácticas reparadoras sobre antiguas obras de tierra, parcial o totalmente desaparecidas, se han documentado también en el castillo de Alhama de Murcia (Baños y Jiménez 2005: p. 322), la muralla de Murcia (Navarro y Jiménez 2007: p. 78), el castillo de Gormaz (Almagro 2008: p. 69) o más recientemente en la Alcazaba de Baza (Caballero en prensa).
} 


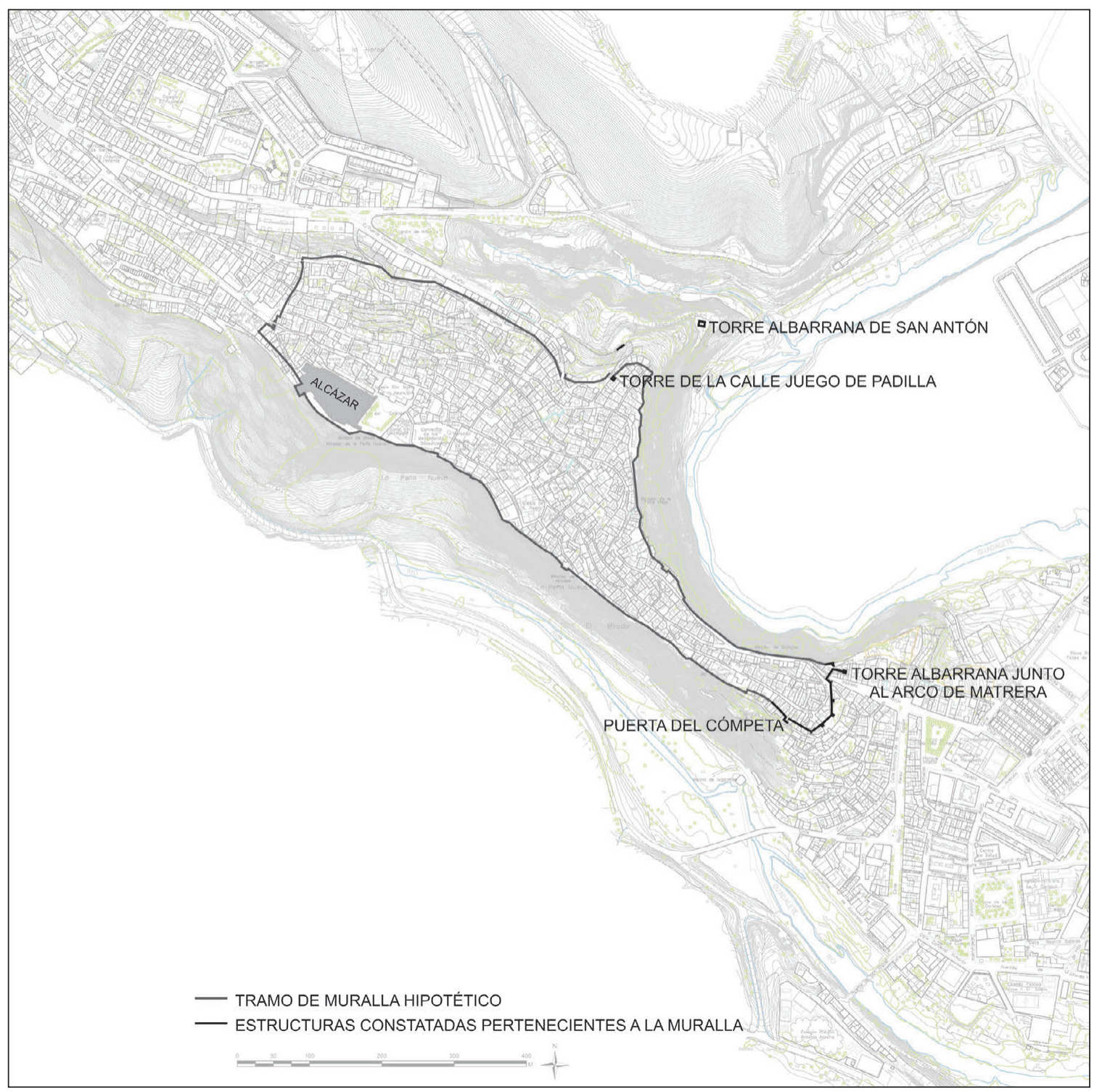

Fig. 19. Plano con la hipótesis del perímetro amurallado de Arcos de la Frontera y las estructuras emergentes constatadas (en negro)

la dificultad que puede suponer el tratar de identificar discontinuidades sobre estructuras terrosas.

En función de lo expuesto en páginas precedentes y respecto a la atribución a una dinastía o entidad estatal de unos determinados patrones constructivos, hemos de tener siempre presentes algunas variables que nos obligan a ser prudentes, como los más de 80 años de poder almohade en la Península Ibérica ${ }^{62}$, la disponibilidad de materiales locales, la capacidad económica del promotor de la obra, etc. A partir de lo cual, y no sin cierta cautela debido al mínimo aporte de los materiales arqueológicos,

\footnotetext{
${ }^{62}$ Si contamos desde la conquista almohade de Sevilla en 1145 hasta el alzamiento de Ibn Hud en Murcia, en 1228.
}

proponemos una datación para el tramo sureste de la cerca arcense en torno a los siglos XI-XII.

En estos momentos Arkus se nos presenta como una población andalusí de modesta superficie ${ }^{63}$ definida mayoritariamente como hisn por las fuentes islámicas ${ }^{64}$, y que por dos veces será cabeza de efímeros estados independientes, alcanzando su período de máximo esplendor hacia el siglo XIII ${ }^{65}$ (Fig. 19).

\footnotetext{
${ }^{63}$ Contando con 14,5 ha de superficie, Arkus pertenecería a la inferior de las tres categorías de poblaciones establecidas por Mazzoli-Guintard en función de la superficie murada; Mazzoli-Guintard 1996: p. 328.

64 Mazzoli-Guintard 1996: p. 316.

65 Viguera 2003: pp. 40-41, Mazzoli-Guintard 1996: p. 193.
} 

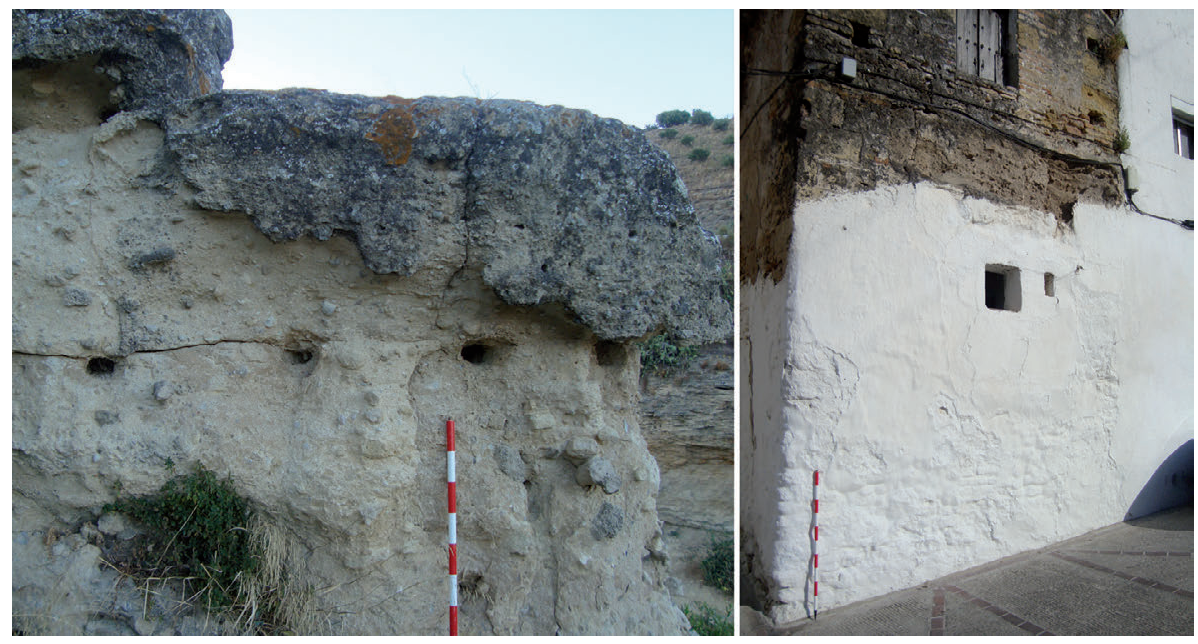

Fig. 20. Restos de la torre albarrana de San Antón (izquierda) y de la torre situada en la calle Juego de Padilla (derecha)
En cuanto a la configuración de la población en estos siglos, aunque la toponimia urbana podría remitirnos a un perímetro murado previo de superficie más reducida ${ }^{66}$, carecemos de datos concluyentes para afirmar que el frente amurallado que hemos estudiado pudiera corresponderse con un posible arrabal. La prospección urbana apenas aportó información al respecto, debido a la existencia generalizada de enjalbegados en las fachadas. No obstante pudimos identificar un par de torres de la muralla: los restos de una de gran tamaño sobre un espolón en el frente norte de la localidad ${ }^{67}, \mathrm{y}$ otro cubo de fábrica muy similar a la documentada en la muralla suroriental, situada en la calle Juego de Padilla (Fig. 20).

Por último, concluimos nuestro trabajo dedicando unas líneas al origen del Arco de Matrera, uno de los objetivos que establecimos al inicio de la investigación. La respuesta a esta cuestión pasa por comparar la contradictoria información ofrecida por las fuentes escritas y la arqueología, para exponer a continuación una hipótesis razonada que pueda explicar tal discordancia. Recordemos cómo la historiografía solo menciona una puerta para el frente suroriental de Arcos de la Frontera (Puerta de Matrera), mientras que el estudio revela que en realidad hubo tres, aunque creemos que nunca llegaron a funcionar simultáneamente: Puerta del Cómpeta, Arco de Matrera y paso de la calle Cardenal Espínola (Fig. 3).

${ }^{66}$ Como podría indicar la calle Torre de la Esquina. En un plano publicado hace unos años sobre Arcos de la Frontera en época medieval, el caserío aparece homogéneo, delimitado únicamente por la muralla que hemos estudiado; Valor 1999: pp. 196-197.

${ }^{67}$ Podría tratarse de la Torre de San Antón, citada por Mancheño 2002: vol. I, p. 44. Pensamos que esta torre o castillete ejercería de albarrana de una barbacana previa a la cerca, la cual se intuye sobre el barranco del Arroyo de las Nieves. Las tapias, de módulo distinto a la muralla, tienen $47 \mathrm{~cm}$ de alto.
Inicialmente, es necesario señalar que los datos extraídos a partir de la documentación escrita son parcos y poco esclarecedores. Por un lado, tan solo podemos afirmar que la alusión más antigua que hemos hallado, emitida hacia $1630^{68}$, nos habla de una Puerta de Matrera hacia 1514, siendo difícil determinar a qué apertura sobre la muralla sureste se estaría refiriendo.

Por otra parte la intervención demostró que la Puerta del Cómpeta estuvo en uso durante época medieval para caer en el olvido tras este período.

Aunque carecemos de datos objetivos y el actual acceso se dataría en época moderna tardía, creemos que el paso de la calle Cardenal Espínola pudo corresponderse con una poterna existente desde época andalusí en un punto discreto y relativamente recóndito de la muralla, lo que justificaría la construcción de la torre albarrana en esa ubicación concreta, la cual junto al precipicio norte de "la peña", constituirían un paso previo a la poterna en forma de estrecho corredor fácilmente defendible. Además, tampoco debemos olvidar que una de las razones de ser principales de estas torres lo constituye la defensa avanzada de puertas ${ }^{69}$.

En función de lo expuesto, barajamos la hipótesis de que, durante la Edad Media, Arcos de la Frontera podría haber contado con dos accesos por su frente sureste, la Puerta del Cómpeta y el paso de la calle Cardenal Espínola. Ante ello planteamos que el actual Arco de Matrera, realizado picando "la peña" bajo la muralla medieval, pudo haberse erigido a partir del siglo XVI, viniendo a sustituir a la Puerta acodada del Cómpeta, evitándose por tanto que la villa careciese de un acceso por este frente oriental en todo momento.

\footnotetext{
68 Gamaza 1771: p. 11.

69 Pavón 1999: p. 254; Mora y Figueroa, 1994: p. 196.
} 
Una vez olvidada la realidad de la frontera, pensamos que la amortización de la puerta en recodo pudo deberse a su propia naturaleza quebrada y defensiva. Ésta resultaba ya ineficaz y obsoleta en unos tiempos en los que nuevas necesidades debían atenderse, en especial el paso de carros que facilitase el comercio y el abastecimiento al interior de la villa. Este hecho llevó a construir un acceso directo más transitable y cómodo que permitiese el crecimiento extramuros del caserío medieval ${ }^{70}$. Ante la ausencia de fuentes escritas para aquella época que seguro hubieron de reflejar tan importante hecho ${ }^{71}$, pensamos que la apertura del nuevo paso a través del recinto se produjo en una coyuntura general de expansión urbana, que por ejemplo, y entre otras ciudades, sí que está atestiguada en Sevilla hacia 1560. Así lo refirió Hernán Ruiz el Joven, maestro mayor de obras del cabildo sevillano por entonces: “... entre las puertas de Macarena, de Córdoba, de la Trinidad, del Sol, de Osario, de la Carne, de Jerez se abran otras puertas de nuevo y se cierren las que ahora están, porque por ellas se va rodeando para salir de la ciudad y será más el ornato de la misma si se abren las puertas aludidas en derecho de las calles, como está la de Triana, y si se derriban de todo punto o se descombran los revellines (barbacanas) que se vienen abajo..."72.

A partir de su posible construcción en el siglo XVI, el actual Arco de Matrera será protagonista, como eje vertebrador, de un segundo gran momento de desarrollo de la ciudad acontecido en el siglo XVIII, acorde con las medidas ilustradas de saneamiento, higiene y expansión urbana. Será entonces cuando definitivamente se consolide el caserío extramuros y se configure el actual Barrio Bajo, tal como ha llegado hasta nuestros días ${ }^{73}$ (Fig. 2).

En cuanto al topónimo de Puerta de Matrera, cabría preguntarse si éste ya existía en el Medievo asociado a la Puerta del Cómpeta o al paso de la calle Cardenal

\footnotetext{
70 Estas nuevas exigencias urbanas se debieron traducir también en el ensanche de las calles, al menos de las principales, tal como denotan, por ejemplo, las ordenanzas de alarifes cordobeses de fines del siglo XV (Escobar 1989: p. 185), o como sucedió en Murcia en el siglo XVI para facilitar el tránsito de carros (Chacón 1979: p. 84), cuyo uso parece que se generaliza en esta época (Torres 1942a: p. 73).

71 Ya apuntamos cómo gran parte de las mismas desaparecieron en 1593. Vid. nota 33.

${ }^{72}$ López 1949: pp. 21-22.

73 En un dibujo fechado en 1760, se aprecia la existencia de casas en lo que hoy es la calle Matrera Abajo; Gamaza 1777: dibujos iniciales. El origen de este barrio se establecería en el siglo XVI, una vez abierto al actual Arco de Matrera, aunque la fisonomía actual del mismo es de finales del siglo XVIII, a tenor del testimonio epigráfico presente en la portada de varios de estos inmuebles, que suelen contar con cuatro crujías y hasta tres plantas, desarrollándose algunas entreplantas en "la peña" horadada, bajo la muralla.
}

Espínola, y por tanto se trasladó al abrir la nueva puerta de trazado recto, o se acuñó ex profeso para el mismo a partir del siglo XVI.

\section{Agradecimientos. Equipo técnico}

Esta actuación fue desarrollada durante el verano de 2011 por encargo del Ayuntamiento arcense, como paso previo a la posterior consolidación y puesta en valor de la muralla. El equipo técnico ha estado formado por D. Manuel María Alonso Ruiz y el Dr. Luis José García Pulido. Por su parte los doctores D. Antonio Almagro Gorbea y D. Antonio Orihuela Uzal han ejercido de asesores científicos. Agradecemos sinceramente las aportaciones del Dr. Pedro Jiménez Castillo y D. Manuel Pérez Asensio. Nuestra gratitud se extiende a D. José Manuel Durán y D. Rafael Rossetti, por el material gráfico y textual que nos facilitaron durante nuestra estancia en Arcos de la Frontera.

\section{Bibliografía}

Aguilar Moya, L. 2000: "Nuevos datos sobre las murallas islámicas de Jerez de la Frontera", Revista de Historia de Jerez, 6, pp. 99-113.

Almagro Gorbea, A. 2008: "La puerta califal del castillo de Gormaz", Arqueología de la Arquitectura, 5, pp. 55-77.

Azuar Ruiz, R. 2004: “Técnicas constructivas y fortificación almohade en alAndalus", en Valor Piechotta, M., Villar Iglesias, J. L. y Ramírez del Río. J. (edits.), Los almohades: su patrimonio arquitectónico y arqueológico en el sur de al-Andalus, pp. 57-74. Consejería de Relaciones Institucionales de la Junta de Andalucía, Sevilla.

Al-Bakri 1982: Geografía de España, kitab al-Masalik wa-l-mamalik, Vidal Beltrán, E. (introducción, notas e índices). Anubar, Zaragoza.

Baños Serrano, J. y Jiménez Castillo, P. 2005: "Excavaciones en el castillo de Alhama de Murcia. Proyecto Castrum”, en Actas de las XVI Jornadas de Patrimonio Histórico; Intervenciones en el patrimonio arquitectónico, arqueológico y etnográfico de la Región de Murcia, pp. 321-322. Murcia.

B. Buluqqin al-Ziri, 'Abd Allah 1980: El siglo XI en primera persona. Las "memorias" de "Abd Allah, último rey zìrí de Granada, destronado por los almorávides (1090), Lévi-Provençal, E. y García Gómez, E. (traducción). Madrid.

Caballero Cobos, A. en prensa: "Análisis de estructuras emergentes; calle Trasgrisolias n ${ }^{\circ} 2$; Baza (Granada)”, en Anuario Arqueológico de Andalucía 2012. Junta de Andalucía. Consejería de Cultura. [en línea].

Chacón Jiménez, F. 1979: Murcia en la centuria del quinientos. Universidad de Murcia, Academia Alfonso X el Sabio, Murcia.

Escobar Camacho, J. M. 1989: "La infraestructura urbana de Córdoba en la Baja Edad Media”, Boletín de la Real Academia de Córdoba de Ciencias, Bellas Letras y Nobles Artes, 117, pp. 183-194.

Fournier Pulido, J. A. y Casado Ariza, M. J. 2007: "Estudio general del registro cerámico, del siglo XII al siglo XVIII”, en Rodríguez, A. (edit.), San Juan de Acre, la historia recuperada de un barrio de Sevilla, pp. 207-232. Envisesa, Sevilla.

Gamaza y Romero de Aragón, P. 1771: Descripción de Arcos por Don Pedro de Gamaza. Archivo de la Institución Colombina de Sevilla, Arcos de la Frontera.

García Fitz, F. 1988: "La frontera Castellano-Granadina a fines del siglo XIII", en Segura Graíño, C. (coord.), Relaciones exteriores del Reino de Granada: IV Coloquio de Historia Medieval Andaluza, pp. 23-35. Almería.

González Jiménez, M. 2003: "Conquista y repoblación de Arcos de la Frontera”, en Actas del I Congreso de Historia de Arcos de la Frontera: con 
motivo del 750 aniversario de la conquista de la ciudad por Alfonso $X$ “el Sabio”, 1253-2003, pp. 9-30. Ayuntamiento de Arcos de la Frontera, Arcos de la Frontera.

Graciani García, A. y Tabales Rodríguez, M. Á. 2008: “El tapial en el área sevillana. Avance cronotipológico estructural”, Arqueología de la Arquitectura, 5 , pp. $135-158$.

Graciani García, A. 2009: "La técnica del tapial en Andalucía occidental”, en Suárez Márquez, Á. (coord.), Construir en Al Andalus, Monografías del Conjunto Monumental de la Alcazaba, 2, pp. 111-140. Almería.

Gurriarán Daza, P. y Sáez Rodríguez, Á. 2002: "Tapial o fábricas encofradas en recintos urbanos andalusíes", en Actas del II congreso internacional La ciudad en al Andalus y el Magreb (Algeciras, 1999), pp. 561-626. Granada.

Gutiérrez López, J. M. y Martínez Enamorado, V. 2003: "Matrera (Villamartín): una fortaleza andalusí en el alfoz de Arcos", en Actas del I Congreso de historia de Arcos de la Frontera: con motivo del 750 aniversario de la conquista de la ciudad por Alfonso X “el Sabio”, 1253-2003, pp. 103-130. Ayuntamiento de Arcos de la Frontera, Arcos de la Frontera.

Hernández, F. J. 1993: Las rentas del Rey. Sociedad y fisco en el reino castellano del siglo XIII. Fundación Ramón Areces, Madrid.

Al-Himyari 1963: Kitab al-Rawd al mi `tar, Maestro González, M. P. (traducción). Anubar, Valencia.

Huarte Cambra, R. y Lafuente Ibañez, P. 2001: "Los siglos X y XI en Isbiliya. Su caracterización cultural a través del registro cerámico”, en Actas del V Congreso de Arqueología Medieval Española, vol. 2, pp. 547-558. Junta de Castilla y León y Asociación Española de Arqueología Medieval, Valladolid.

Ibn Abi Zar` 1964: Rawd al-qirtas, Huici Miranda, A. (traducción). Anubar, Valencia.

Ibn Hayyan 1981: Crónica del califa 'Abd al-Rahman III an-Nasir entre los años 912 y 942 (al-Muqtabis V), Viguera Molins, M. J. y Corriente Córdoba, F. (traducción, notas e índices). Anubar, Zaragoza.

Ibn Hayyan 2001: Crónica de los emires Alhakam I y 'Abdarrahman II entre los años 796 y 847 (Almuqtabis II-1), Makki, M. A. y Corriente Córdoba, F. (traducción, notas e índices). Instituto de Estudios Islámicos y del Oriente Próximo, Zaragoza.

Ibn Jaldun 2008: Introducción a la Historia Universal (al-Muqaddimah), Ruiz Girela, F. (edición y traducción). Almuzara, Córdoba.

Al-Idrisi 1974: Geografía de España, Dozy, R. y Goeje, M. J. (textos preparados). Anubar, Valencia.

Íñiguez Sánchez, M. C. y Mayorga Mayorga, J. F. 1993: "Un alfar emiral en Málaga”, en Malpica Cuello, A. (edit.), La cerámica altomedieval en el sur de al-Andalus, pp. 117-138, Monografía Arte y Arqueología Universidad de Granada, Granada.

Jiménez Esteban, J. 1972: "Puertas en recodo y puertas mudéjares", Castillos de España, 75, pp. 22-47.

Lévi-Provençal, É. y García Gómez, E. 1950: Una crónica anónima de 'Abd al-Rahman III al-Nasir. Consejo Superior de Investigaciones Científicas, Instituto Miguel Asín, Madrid-Granada.

López Martínez, C. 1949: El arquitecto Hernán Ruiz en Sevilla. Sevilla.

Madoz Ibáñez, P. 1846-50: Diccionario geográfico-estadístico-histórico de España y sus posesiones de Ultramar. Madrid. [Copia digital realizada por la Biblioteca de Andalucía].

Maíllo Salgado, F. 1991: Crónica anónima de los reyes de taifas. Akal, Madrid.

Mancheño y Olivares, M. 2002: Apuntes para una historia de Arcos de la Frontera, II vols. Servicio de publicaciones de la Universidad de Cádiz, Cádiz.

Márquez Bueno, S. y Gurriarán Daza, P. 2003: "La muralla almohade de Cáceres: aspectos constructivos, formales y funcionales", Arqueología y Territorio Medieval, 10, 1, pp. 57-118.

Márquez Bueno, S. y Gurriarán Daza, P. 2008: "Recursos formales y constructivos en la arquitectura militar almohade de al-Andalus", Arqueología de la Arquitectura, 5, pp. 115-134.

Mazzoli-Guintard, C. 1996: Villes d`al-Andalus. L`Espagne et le Portugal à l'époque musulmane (VIII-XV siècles). Presses Universitaires de Rennes, Rennes.
Menéndez Fueyo J. L., Azuar Ruiz, R., Lozano Olivares F. J. y Llopis García M. T. 1994: "El falso despiece de sillería en las fortificaciones de tapial de época almohade en al-Andalus", en Actas del I congreso de Castellología Ibérica, pp. 481-511. Palencia.

Menéndez Robles, M. L. y Reyes Téllez, F. 1987: "Estructuras defensivas de una ciudad almohade: Jerez de la Frontera", en Actas del II Congreso de Arqueología Medieval Española, t. II, pp. 765-772. Comunidad de Madrid, Madrid.

Molina Martínez, L. (ed. y trad.), 1983: Una descripción anónima de al-Andalus (Dikr bilad al-Andalus), II vols. Consejo Superior de Investigaciones Científicas, Madrid.

Mora y Figueroa, L. 1994: Glosario de arquitectura defensiva medieval. Servicio de publicaciones de la Universidad de Cádiz, Cádiz.

Navarro Palazón, J. y Jiménez Castillo, P. 2007: Las ciudades de Alandalús, nuevas perspectivas. Instituto de Estudios Islámicos y del Oriente Próximo, Zaragoza.

Navarro Palazón, J. y Jiménez Castillo, P. 2011: "Materiales y técnicas constructivas en la Murcia andalusí (siglos X-XIII)", Arqueología de la Arquitectura, 8, pp. 85-120.

Pavón Maldonado, B. 1999: Tratado de arquitectura hispanomusulmana Vol. II, Ciudades y fortalezas. Consejo Superior de Investigaciones Científicas, Madrid.

Pérez Macías, J.A., Rodrigo Cámara, J. M., Gómez Toscano, F. y Campos Carrasco, J. M. 1998: "Las murallas de Madina Labla (Niebla, Huelva)", en Actas I CongresoInternacional Fortificaciones enal-Andalus, pp.347-352.Algeciras.

Pérez Regordán, M. 2002: La historia de Arcos a través de sus calles. Arcos de la Frontera.

Retuerce Velasco, M. 1998: La cerámica andalusí de la Meseta. Editorial CRAN, Madrid.

Retuerce Velasco, M. y Hervás Herrera, M. A. 1999: “Calatrava la vieja. Fortificación de una ciudad islámica de la meseta", Castillos de España, 113 , pp. 23-43.

Richarte García, M. J. y Aguilera Rodríguez, L. 2003: "La ciudad de Qalsana (Junta de los Ríos, Arcos de la Frontera) desde una perspectiva históricoarqueológica”, en Actas del I Congreso de Historia de Arcos de la Frontera: con motivo del 750 aniversario de la conquista de la ciudad por Alfonso X “el Sabio”, 1253-2003, pp. 87-102. Ayuntamiento de Arcos de la Frontera, Arcos de la Frontera.

Sánchez Saus, R. 2003: "Los linajes medievales de Arcos de la Frontera", en Actas del I Congreso de Historia de Arcos de la Frontera: con motivo del 750 aniversario de la conquista de la ciudad por Alfonso X "el Sabio", 1253-2003, pp. 195-220. Ayuntamiento de Arcos de la Frontera, Arcos de la Frontera.

Souto Lasala, J. A. 2005: El conjunto fortificado islámico de Calatayud. Zaragoza. Instituto de Estudios islámicos y del Próximo Oriente, Zaragoza.

Tabales Rodríguez, M. Á. 2000: “Aportaciones de la Arqueología medieval al conocimiento de las técnicas constructivas", en Graciani García, A. (coord.), La técnica de la arquitectura medieval, pp. 35-74. Sevilla.

Tabales Rodríguez, M. Á. 2002: Sistema de análisis arqueológico de edificios históricos, Universidad de Sevilla. Sevilla.

Toledo Jordán, J. M. 1985-1986: "Unas notas para el estudio geográficoadministrativo del Garb Al-Andalus: la Cora de Sidonia”, Estudios de historia y de arqueología medievales, 5 y 6, pp. 43-52.

Torres Balbás, L. 1941: "La alcazaba almohade de Badajoz", Al-Andalus, VI, pp. 168-203.

Torres Balbás, L. 1942a: "Las ciudades musulmanas y su urbanización", Revista de Estudios de la Vida Local, 6, pp. 59-80.

Torres Balbás, L. 1942b: "Las torres albarranas", Al-Andalus, VII, pp. 216-220. Torres Balbás, L. 1949: Arte Almohade. Arte Nazarí. Arte Mudéjar, Ars Hispaniae, Historia Universal del Arte Hispánico, vol. IV. Editorial Plus Ultra, Madrid.

Torres Balbás, L. 1960: "Las puertas en recodo en la arquitectura militar hispanomusulmana”, Al-Andalus, XXV, 2, pp. 419-444.

Triki, H. 1999: "Arcos de la Frontera", en Itinerario cultural de almorávides y almohades. Magreb y Península Ibérica, pp. 196-197. Fundación El Legado Andalusí, Granada. 
Vallvé Bermejo, J. 1986: La división territorial de la España musulmana. Instituto de Filología, Madrid.

Valor Piechotta, M. 1991: La arquitectura militar y palatina en la Sevilla musulmana. Diputación provincial de Sevilla, Sevilla.

Valor Piechotta, M. 1999: "Recinto amurallado de Arcos", en Itinerario cultural de almorávides y almohades, Magreb y Península Ibérica, p. 196, Fundación El Legado Andalusí, Granada.
Viguera Molins, M. J. 2003: "Arcos en al-Andalus: notas sobre su historia islámica”, en Actas del I Congreso de Historia de Arcos de la Frontera: con motivo del 750 aniversario de la conquista de la ciudad por Alfonso $X$ "el Sabio", 1253-2003, pp. 31-54. Ayuntamiento de Arcos de la Frontera, Arcos de la Frontera. 